\title{
Comparative Genomics Screen Identifies Microbe-Associated Molecular Patterns from 'Candidatus Liberibacter' spp. That Elicit Immune Responses in Plants
}

\author{
Yuan Chen, Claire Bendix, and Jennifer D. Lewis ${ }^{\dagger}$ \\ Plant Gene Expression Center, United States Department of Agriculture-Agricultural Research Service and Department of Plant \\ and Microbial Biology, University of California-Berkeley, 800 Buchanan Street, Albany, CA 94710, U.S.A.
}

Accepted 27 November 2019.

Citrus huanglongbing (HLB), caused by phloem-limited 'Candidatus Liberibacter' bacteria, is a destructive disease threatening the worldwide citrus industry. The mechanisms of pathogenesis are poorly understood and no efficient strategy is available to control HLB. Here, we used a comparative genomics screen to identify candidate microbeassociated molecular patterns (MAMPs) from ' $\mathrm{Ca}$. Liberibacter' spp. We identified the core genome from multiple ' $\mathrm{C}$. Liberibacter' pathogens, and searched for core genes with signatures of positive selection. We hypothesized that genes encoding putative MAMPs would evolve to reduce recognition by the plant immune system, while retaining their essential functions. To efficiently screen candidate MAMP peptides, we established a high-throughput microtiter plate-based screening assay, particularly for citrus, that measured reactive oxygen species (ROS) production, which is a common immune response in plants. We found that two peptides could elicit ROS production in Arabidopsis and Nicotiana benthamiana. One of these peptides elicited ROS production and defense gene expression in HLB-tolerant citrus genotypes, and induced MAMP-triggered immunity against the bacterial pathogen Pseudomonas syringae. Our findings identify MAMPs that boost immunity in citrus and could help prevent or reduce HLB infection.

Keywords: 'Candidatus Liberibacter' species, citrus, citrus greening, defense signaling pathways, elicitors, genomics, huanglongbing, MAMPs, microbe-associated molecular patterns, PAMPs,

${ }^{\dagger}$ Corresponding author: J. D. Lewis; jdlewis@berkeley.edu, Jennifer.lewis@usda.gov

Funding: Research on plant immunity in the Lewis laboratory was supported by the United States Department of Agriculture-Agricultural Research Service (ARS 2030-21000-046-00D and 2030-21000-050-00D (to J. D. Lewis), the ARS Research Associate Program Class of 2015, and the National Science Foundation Directorate for Biological Sciences IOS1557661 (to J. D. Lewis).

*The $\boldsymbol{e}$-Xtra logo stands for "electronic extra" and indicates that supplementary figures and supplementary tables are published online.

The author(s) declare no conflict of interest.

This article is in the public domain and not copyrightable. It may be freely reprinted with customary crediting of the source. The American Phytopathological Society, 2020. pattern-triggered immune response, plant responses to pathogens, reactive oxygen species

Citrus greening or huanglongbing (HLB) is a destructive disease that threatens the worldwide citrus industry. The disease is mainly caused by three gram-negative bacteria: ' $\mathrm{Can}$ didatus Liberibacter asiaticus', ' $C a$. L. africanus', and ' $C a$. L. americanus' (Gottwald 2010). The bacterium is transmitted by the citrus psyllid Diaphorina citri and colonizes the phloem of citrus (Bové 2006; Pelz-Stelinski et al. 2010). Infected citrus trees exhibit blotchy mottle and asymmetrical chlorosis on the leaves, discolored and bitter-tasting fruit, a short lifespan, and low productivity (da Graça et al. 2016). In the United States, the disease has already caused huge losses in Florida's citrus industry and is spreading to other major areas of production in Texas and California (Wang and Trivedi 2013). Diverse methods have been applied to control HLB disease (Wang et al. 2017) such as the use of antimicrobial compounds (Zhang et al. 2011), plant hormones (Canales et al. 2016; Nehela et al. 2016), and thermotherapy (Hoffman et al. 2013). However, unfortunately, there is very limited means of controlling HLB in the field (Li et al. 2016). One of the major factors contributing to the rapid spread and devastation of HLB is the lack of natural resistance in hosts. Identifying infected trees is also challenging because HLB symptoms may not appear for more than 1 year after initial infection (Gottwald 2010; Manjunath et al. 2008). Bacterial colonization appears to be quite slow, perhaps due, in part, to its niche in the phloem (Bendix and Lewis 2018; Wang et al. 2017). In addition, ' $C a$. L. asiaticus', ' $C a$. L. africanus', and ' $C a$. L. americanus' have been recalcitrant to culturing, which has limited further exploration of genetic factors contributing to virulence or recognition. As a result, there has been much interest in exploring plant innate immunity against ' $\mathrm{Ca}$. Liberibacter' spp. (da Graça et al. 2016).

Plant immune response to biotrophic pathogens can be divided into microbe-associated molecular pattern (MAMP)triggered immunity (MTI) and effector-triggered immunity (ETI). MAMPs are recognized by membrane localized pattern recognition receptors (PRRs), which are commonly receptorlike kinases (RLKs) or receptor-like proteins (Segonzac and Zipfel 2011). The best characterized MAMP is flg22, from the highly conserved N-terminal domain of flagellin in Pseudomonas aeruginosa, which is recognized by the PRR FLAGELLIN-SENSING 2 (FLS2) in Arabidopsis (Boller and 
Felix 2009; Felix et al. 1999; Gómez-Gómez and Boller 2000). MTI induces a suite of immune responses, including reactive oxygen species (ROS) production, $\mathrm{Ca}^{2+}$ fluxes, stomatal closure, callose deposition, mitogen-activated protein kinase (MAPK)-dependent signal transduction, defense gene expression, and hormone biosynthesis (Boller and Felix 2009; Macho and Zipfel 2015). Successful pathogens attenuate MTI by delivering effectors to evade or suppress host immunity (Clark et al. 2018; Lewis et al. 2009; Toruño et al. 2016; Xin et al. 2018). These pathogenic proteins, when recognized in the cytoplasm by nucleotide-binding leucine-rich repeat proteins, trigger a second layer of plant defense, called ETI (Jones and Dangl 2006; Schreiber et al. 2016). ETI is an amplified MTI response (Jones and Dangl 2006; Tao et al. 2003; Tsuda and Katagiri 2010), resulting in rapid cell death at the infection site (Heath 2000; Wright and Beattie 2004).

Because many MAMPs are part of highly conserved molecules such as flagellin, elongation factor Tu (EF-Tu), and peptidoglycan, the MAMP-encoding gene is inferred to be essential for the pathogen (Gust et al. 2007; Kacar et al. 2017; Kunze et al. 2004; Zipfel et al. 2004). As a result, this means that a pathogen cannot easily lose a gene encoding a MAMP to avoid recognition. However, selection for variation within a MAMP might reduce its recognition by the plant immune system. Several comparative genomic studies identified core genes with signs of selection in Pseudomonas syringae or Ralstonia solanacearum (Eckshtain-Levi et al. 2018; McCann et al. 2012; Mott et al. 2016). Given the difficulties in manipulating HLB pathogens and the disease's long latency period, we pursued a bioinformaticsbased comparative genomics screen to identify potential MAMPs from ' $\mathrm{Ca}$. Liberibacter' spp. We identified 13 candidate MAMPs from ' $C a$. Liberibacter' genomes, and screened for immune responses to candidate MAMPs in Arabidopsis, Nicotiana benthamiana, and citrus species. We identified two new MAMPs that elicit MTI. This study identifies new targets to boost the host immune system and potentially control HLB.

\section{RESULTS}

\section{Computational identification of candidate MAMPs.}

To identify putative MAMPs, we employed a computational comparative evolutionary genomics approach. MAMPencoding genes are inferred to be essential for the pathogen because they are highly conserved. However, because MAMPs are recognized by the host, this creates strong evolutionary pressure on the pathogen to diversify parts of the protein that are not essential for its activity and that could lessen recognition by the plant immune system (McCann et al. 2012). Therefore, we sought to identify core genes (Supplementary
Table S1) with signatures of positive selection (Supplementary Fig. S1). We took advantage of publicly available genome sequences for ' $\mathrm{Ca}$. L. asiaticus' (seven strains), ' $\mathrm{Ca}$. L. africanus' (one strain), 'Ca. L. americanus' (two strains), 'Ca. L. solanacearum' (four strains), and Liberibacter crescens (two strains) to identify core and accessory genes using Roary (Page et al. 2015). We used codeml and Bayes empirical Bayes estimates to identify core genes under positive selection (Yang 2007; Yang et al. 2000, 2005).

We hypothesized that genes under positive selection would be shared by citrus-infecting strains (' $\mathrm{Ca}$. L. asiaticus', ' $C a$. L. africanus', and ' $C a$. L. americanus') and possibly ' $C a$. L. solanacearum', which infects solanaceous plants, but not L. crescens, which is nonpathogenic (Fagen et al. 2014; Naranjo et al. 2019). Therefore, to refine our list of candidate MAMPs, we performed a second round of analysis to identify core genes that were shared between ' $\mathrm{Ca}$. L. asiaticus' and related strains, and were not under selection in L. crescens. We used codeml and Bayes estimates to identify core genes under positive selection in ' $\mathrm{Ca}$. L. asiaticus' strain psy62, because ' $C a$. L. asiaticus' had the most strains available (Yang 2007; Yang et al. 2000, 2005). We prioritized 13 candidate MAMPs (Table 1) for further study because they contained multiple sites of positive selection, and an additional candidate peptide because it was associated with the flagella. We designed and synthesized 20 to 26 amino acid peptides that encompassed the positively selected sites in the candidate proteins.

\section{Candidate MAMPs elicit ROS production.}

Apoplastic peroxidase (POX) is critical for generating ROS during pathogen invasion, as part of a concerted plant immune response (Daudi et al. 2012; O'Brien et al. 2012). To determine whether candidate MAMPs could elicit immune responses, we carried out a colorimetric assay for POX activity. The POX assay is highly sensitive, and allows for the detection of weak MAMPs (Mott et al. 2018). After sampling and washing leaf tissue to prevent the detection of POX activity from wounding (Minibayeva et al. 2009), we incubated the candidate MAMP with the tissue, and assayed for ROS production using 5-aminosalicylic acid. We first tested the candidate MAMPs in Arabidopsis thaliana and N. benthamiana, because they are better characterized systems for detecting ROS activity and because plants may differ in their ability to detect MAMPs, as seen with the recognition of EF-Tu by the EFR receptor (Lacombe et al. 2010). We used flg22, a wellcharacterized MAMP (Zipfel et al. 2004), as a positive control. At low concentrations of peptide $(10 \mathrm{nM}, 100 \mathrm{nM}$, or $1 \mu \mathrm{M})$, we were unable to detect POX activity in Arabidopsis. When tested at $10 \mu \mathrm{M}$, pksG and nuoD in Murashige and

Table 1. Candidate microbe-associated molecular patterns used in this article

\begin{tabular}{lclc}
\hline Peptide name & PSS $^{\mathbf{a}}$ & \multicolumn{1}{c}{ Peptide } & Gene description \\
\hline dnaG & 3 & KQIAQVTAKGEAEKTAILIS & DNA primase \\
pksG & 3 & SILEIEDITGIYTNDCMDFWR & $\begin{array}{c}\text { Polyketide biosynthesis/hydroxymethylglutaryl-CoA } \\
\text { synthase }\end{array}$ \\
lpxK & & SGKKVLAFSGIADTEKFFTT & Threonine-tRNA ligase \\
thrS & 4 & SHEKARELFESKKEAYKVE & NADH-quinone oxidoreductase subunit D \\
nuoD & 3 & FKQRNVNIGTVKLEDAWGWG & Flagellar basal-body rod protein \\
flgG & 2 & GSGVQISSVRNVYTQGEVVH & Arginosuccinate synthase \\
argG & 1 & IDFQRGDPIAINGQVMSPEVLLEQ & DNA gyrase subunit A \\
gyrA & 2 & AFVAFREEVVVRRTKYLLNKARD & Primosomal protein N/phosphoribosyl isomerase A \\
priA & 2 & SAIYSQSCVVCGSSGKMIACGFGIER & Acyl-CoA dehydrogenase \\
aidB & 2 & NQVHQPSDSLFALNQPPLFIGMN & UvrABC system protein C \\
uvrC & 2 & EISFFKQYGYKVKITVPKQGEKRKI & 3-Oxoacyl-synthase 1/ $\beta$-ketoacyl synthase \\
fabB & 2 & HSLGAAGAQEAIYCLIMMQERF & GMP synthase \\
guaA & 2 & AFLIYEAIGINLTCVLVDHGFMRKN & \\
\hline
\end{tabular}

${ }^{\text {a }}$ PSS = positively selected sites, shown in bold in peptide sequence. 
Skoog (MS) media induced higher ROS production than MS media alone. However, the overall absorbance was still much lower than that induced by flg22 (Supplementary Fig. S2). At $20 \mu \mathrm{M}$, we saw statistically significantly increased absorbance for nuoD, which was more comparable with that induced by flg22 (Fig. 1A). However, pksG displayed similar levels of POX activity when tested at $10 \mu \mathrm{M}$ or $20 \mu \mathrm{M}$ (Fig. 1A; Supplementary Fig. S2). We noticed that pksG contains $48 \%$ hydrophobic residues, which can impair its ability to dissolve in MS. Thus, we tested pksG in phosphate-buffered saline (PBS), amended with ammonium bicarbonate (PBS-A), which can improve peptide solubility. pksG triggered statistically significantly increased POX activity when tested at a lower concentration $(5 \mu \mathrm{M})$ in PBS-A buffer, presumably because it was more soluble. Interestingly, $1 \mu \mathrm{M}$ flg 22 in PBS-A buffer showed decreased absorbance compared with $1 \mu \mathrm{M}$ flg22 in water (Fig. 1B).
Because peptides may be differentially recognized in hosts, we then tested these MAMP candidates in $N$. benthamiana. Our MAMPs elicited weaker responses in $N$. benthamiana compared with Arabidopsis. Only nuoD had slightly increased absorbance when tested at $30 \mu \mathrm{M}$ (Supplementary Fig. S2). At $50 \mu \mathrm{M}$, nuoD showed consistently increased and statistically significant absorbance, comparable with that induced by flg22, while the other MAMP candidates showed only slightly increased absorbance (Fig. 1C). We also tested pksG or flg22 in the PBS-A buffer, and found that pksG triggered increased POX activity at $20 \mu \mathrm{M}$, while $1 \mu \mathrm{M}$ flg22 elicited a similar response as in Arabidopsis (Fig. 1D).

To further confirm that nuoD and pksG induced ROS responses, we carried out luminol-based ROS assays. Only pksG elicited high levels of ROS production (approximately 200 relative light units [RLU]) (Fig. 2A, B, I, and J) in Arabidopsis and $N$. benthamiana, which were higher than those elicited by flg22 in PBS-A buffer (approximately 80 to 100 RLU)
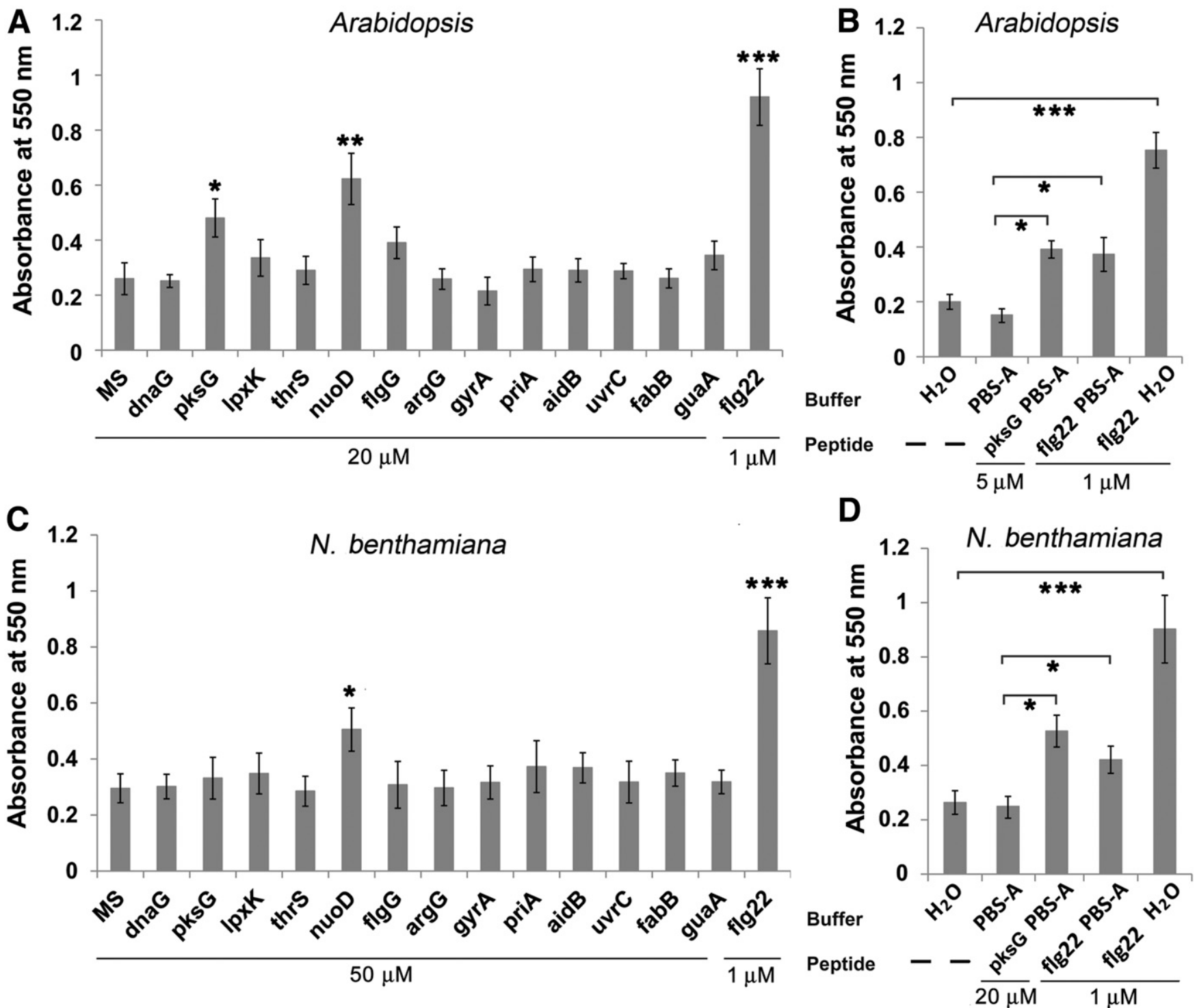

Fig. 1. Some candidate microbe-associated molecular patterns (MAMPs) elicit reactive oxygen species production in the peroxidase (POX) assay in Arabidopsis and Nicotiana benthamiana. POX activity was measured after MAMP treatment. Asterisks indicate significant differences (mean \pm standard deviation, $n=10$ ). Statistical significance was assessed by $t$ tests, where $*, * *$, and $* * *$ indicate $P<0.05,0.01$, and 0.001 , respectively. Each experiment was repeated three times with similar results. A, POX activity in Arabidopsis with Murashige and Skoog (MS) medium, $1 \mu \mathrm{M}$ flg22, or $20 \mu \mathrm{M}$ candidate MAMP. B, POX activity in Arabidopsis with $\mathrm{H}_{2} \mathrm{O}$, phosphate-buffered saline amended with ammonium bicarbonate (PBS-A) buffer, $5 \mu \mathrm{M}$ pksG, $1 \mu \mathrm{M}$ flg22 in PBS-A buffer, or $1 \mu \mathrm{M}$ flg22 in $\mathrm{H}_{2} \mathrm{O}$. C, POX activity in Nicotiana benthamiana with MS, $1 \mu \mathrm{M}$ flg22, or $50 \mu \mathrm{M}$ candidate MAMP. D, POX activity was measured after treatment in $N$. benthamiana with $\mathrm{H}_{2} \mathrm{O}$, PBS-A buffer, $20 \mu \mathrm{M}$ pksG, $1 \mu \mathrm{M}$ flg22 in PBS-A buffer, or $1 \mu \mathrm{M}$ flg22 in $\mathrm{H}_{2} \mathrm{O}$. 
(Fig. 2C, D, I, and J). As expected, flg22 in water elicited high levels of ROS production (1,500 to 2,500 RLU) (Supplementary Fig. S3) in both species, indicating that the PBS-A buffer had a strong dampening effect on MAMP activity. We could not detect the ROS burst from treatment with nuoD within $60 \mathrm{~min}$, even when we increased the peptide concentration to $200 \mu \mathrm{M}$. To exclude the possibility that high concentrations of peptide could cause ROS production, we tested
thrS as a control. thrS carries three positively selected sites but it did not elicit an ROS burst when tested at 100 or $200 \mu \mathrm{M}$ in either species (Fig. 2E, F, I, and J) (data not shown). Thus, high peptide concentrations alone are not sufficient to trigger ROS responses. To exclude the possibility that our candidate peptides were contaminated with flg22, we tested pksG and nuoD in Arabidopsis ecotype Wassilewskija (Ws) (Supplementary Fig. S4), which is insensitive to flg22. pksG and

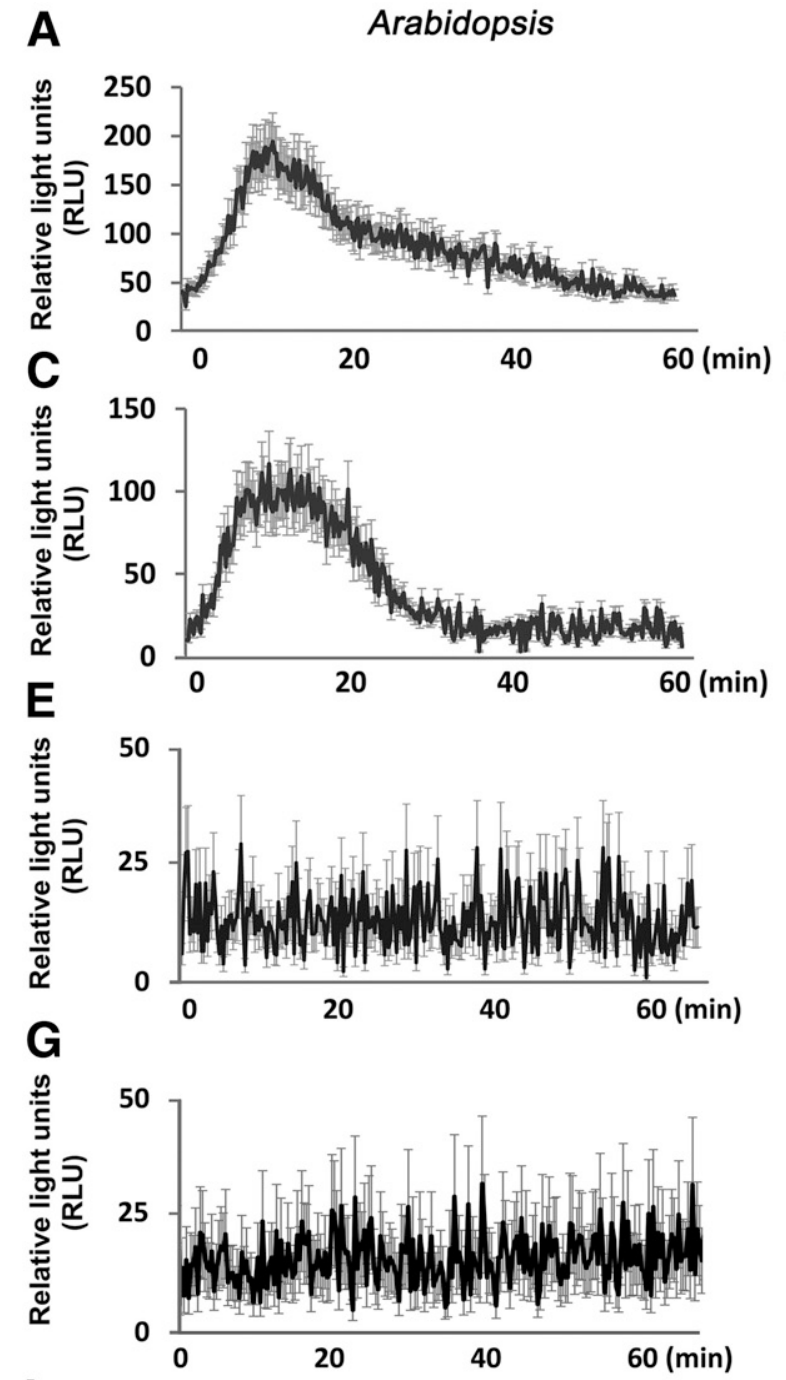

B N. benthamiana
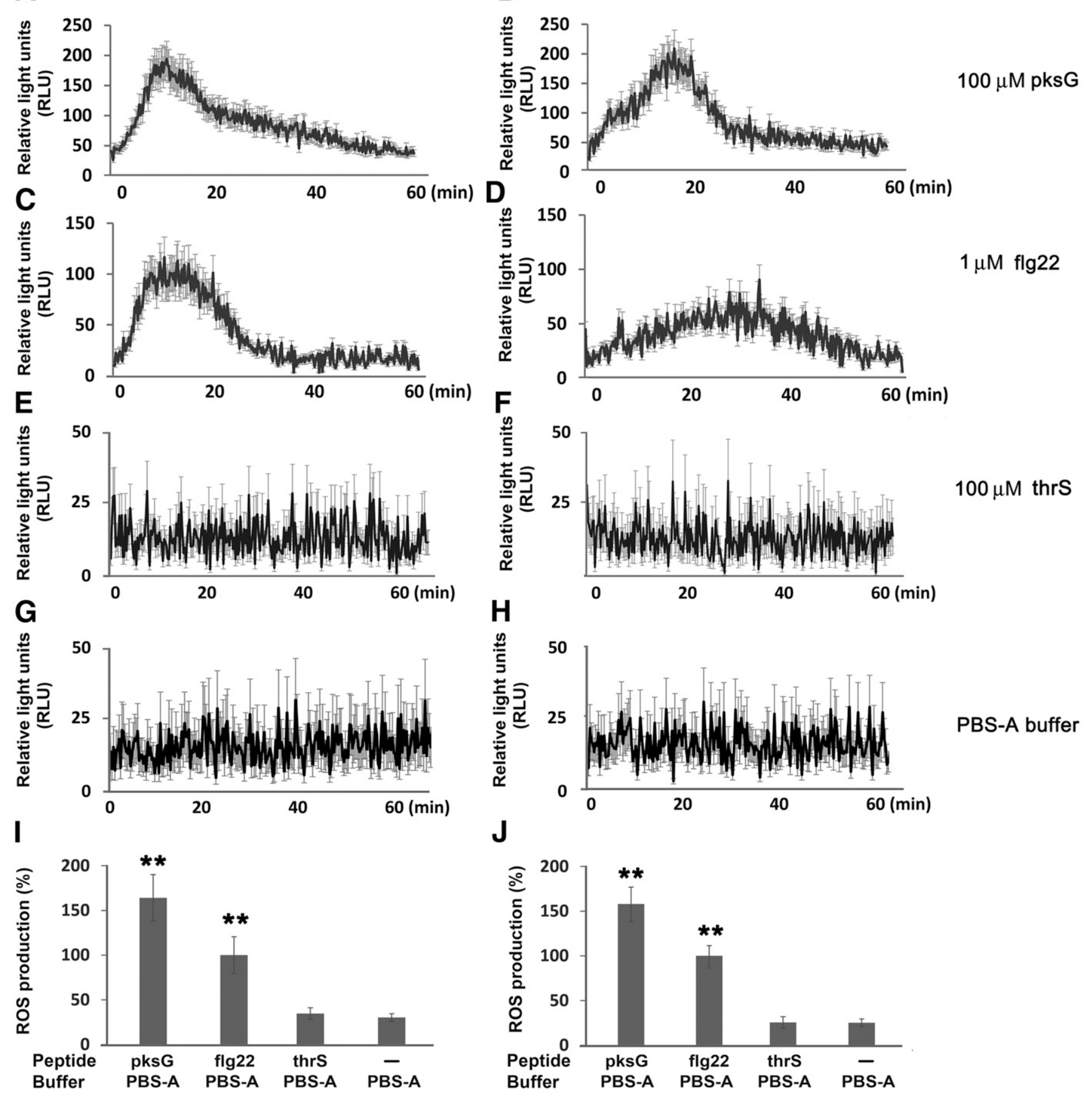

$\mathbf{J}$

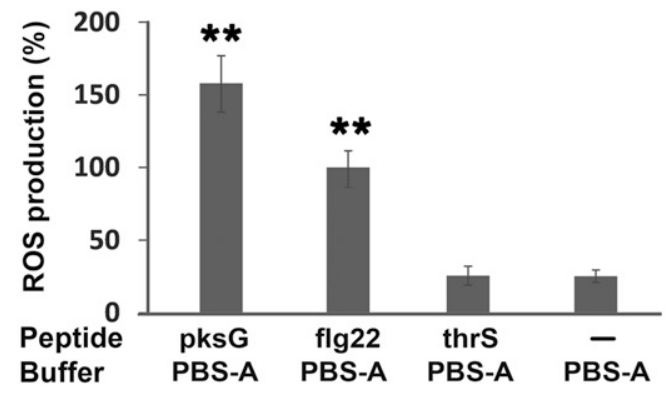

Fig. 2. pksG triggers the reactive oxygen species (ROS) burst in Arabidopsis and Nicotiana benthamiana. Luminol-based assay for ROS production in Arabidopsis or $N$. benthamiana. Peptides were added to leaf disks at $0 \mathrm{~min}$, and relative light units (RLU) were measured for $60 \mathrm{~min}$. Data are shown as mean \pm standard deviation, $n=6$. A and $\mathbf{B}$, Treatment with $100 \mu \mathrm{M} \mathrm{pksG}$ in phosphate-buffered saline amended with ammonium bicarbonate (PBS-A) buffer. C and $\mathbf{D}$, Treatment with $1 \mu \mathrm{M}$ flg22 in PBS-A buffer. E and F, Treatment with $100 \mu \mathrm{M}$ thrS in PBS-A buffer. $\mathbf{G}$ and $\mathbf{H}$, Treatment with PBS-A buffer. I and J, Total ROS production was calculated by integrating the area under the curve and normalizing the flg 22 treatment to $100 \%$. The average of four independent experiments is shown. Error bars represent standard error. Asterisks indicate statistically significant differences compared with the flg22 treatment. Statistical significance was assessed by $t$ tests, where $* *$ indicates $P<0.01$. 
nuoD both elicited an ROS burst in Ws, confirming that the activity arises from the peptide elicitors and is not due to contaminating flg22 peptide.

The differential responses to nuoD in the POX and luminol assays suggested to us that nuoD was a weak MAMP, with activity below the limit of detection in the luminol assay. Therefore, we wondered if the positively selected sites in nuoD were poorly recognized due to the peptide's secondary structure. We constructed several variants of nuoD that retained the positively selected "GT" sites but were extended toward the N terminus or $\mathrm{C}$ terminus of the protein (Fig. 3A). We then tested the nuoD variants again in Arabidopsis using the POX assay. At $20 \mu \mathrm{M}$, nuoDII-25, with the GT site at the $\mathrm{N}$ terminus of the peptide, displayed increased absorbance compared with nuoD, whereas nuoDIV-25 and nuoDV-25, with C-terminal GT sites, induced lower absorbance than nuoD (Fig. 3B). nuoDIII-25 and nuoDVI-25, both of which had internal GT sites, induced less but still statistically significant increases in ROS production (Fig. 3B). Because nuoDII-25 elicited the strongest ROS production, we then tested it in the luminol assay. At $200 \mu \mathrm{M}$, nuoDII-25 induced an ROS burst within $30 \mathrm{~min}$ in Arabidopsis (Supplementary Fig. S5A, C, and E). In N. benthamiana, only nuoD and nuoDII-25 induced statistically significant increases in ROS production in the POX assay (Fig. 3C). Using the luminol assay in $N$. benthamiana, nuoDII-25 showed a slightly delayed ROS burst peaking at 60 min (Supplementary Fig. S5B, $\mathrm{D}$, and F). Thus, based on ROS output alone, nuoD and nuoDII25 are quite weak MAMPs.

Taken together, these results indicate that pksG, nuoD, and nuoDII-25 can act as MAMPs in Arabidopsis and $N$. benthamiana, and elicit different levels of ROS production.

\section{MAMP flg22 triggers a second ROS burst} while candidate MAMPs do not.

ROS responses are typically detected for short periods (within $60 \mathrm{~min}$ ) after peptide treatment. Several groups have shown that MAMPs can elicit a delayed ROS response that is much weaker than the initial ROS burst (Segonzac et al. 2011;
Shang-Guan et al. 2018). Because even high concentrations of some of our peptides did not elicit a rapid ROS burst in Arabidopsis or $N$. benthamiana, we performed time-course experiments for ROS production $12 \mathrm{~h}$ after peptide treatment. As expected, flg22 displayed an initial, very strong ROS burst within $1 \mathrm{~h}$ and a second, long-lasting ROS burst approximately 2 to $4 \mathrm{~h}$ after MAMP application in $N$. benthamiana but not in Arabidopsis (Supplementary Fig. S6A). Therefore we focused on $N$. benthamiana to investigate the second ROS burst.

Although ROS are largely produced in the apoplast (Mignolet-Spruyt et al. 2016), they can also be produced in intracellular compartments, including the chloroplast, peroxisome, and mitochondria (Camejo et al. 2016). To determine whether the second ROS burst was produced inside or outside of the cell, we employed a cell membrane-impermeable derivative of luminol, isoluminol (Shang-Guan et al. 2018), which allowed us to measure ROS production in the apoplast. We adjusted the isoluminol concentration relative to luminol to achieve a similar magnitude of flg22-triggered apoplastic ROS burst (Supplementary Fig. S6A and B). Using isoluminol as substrate, flg22 showed only a single, rapidly appearing peak within 60 min (Supplementary Fig. S6B), indicating that the second ROS burst occurred in intracellular compartments. Having established that we could detect the second ROS burst in $N$. benthamiana, we then tested our candidate MAMPs. However, none of the candidate peptides triggered a second ROS burst in N. benthamiana (Supplementary Fig. S7).

\section{MAMPs elicit ROS production in citrus species.}

Because some of our candidate MAMPs could trigger ROS production in Arabidopsis or N. benthamiana, we then turned to assaying ROS production in citrus species. Citrus species exhibit differing levels of ROS production in response to MAMPs such as flagellin from Xanthomonas citri (Pitino et al. 2015). Therefore, we selected a range of citrus species based on reports of HLB tolerance (Mexican key lime, Australian finger lime, and Eureka lemon), HLB susceptibility (Clementine mandarin, Minneola tangelo, Rio Red grapefruit, and Valencia
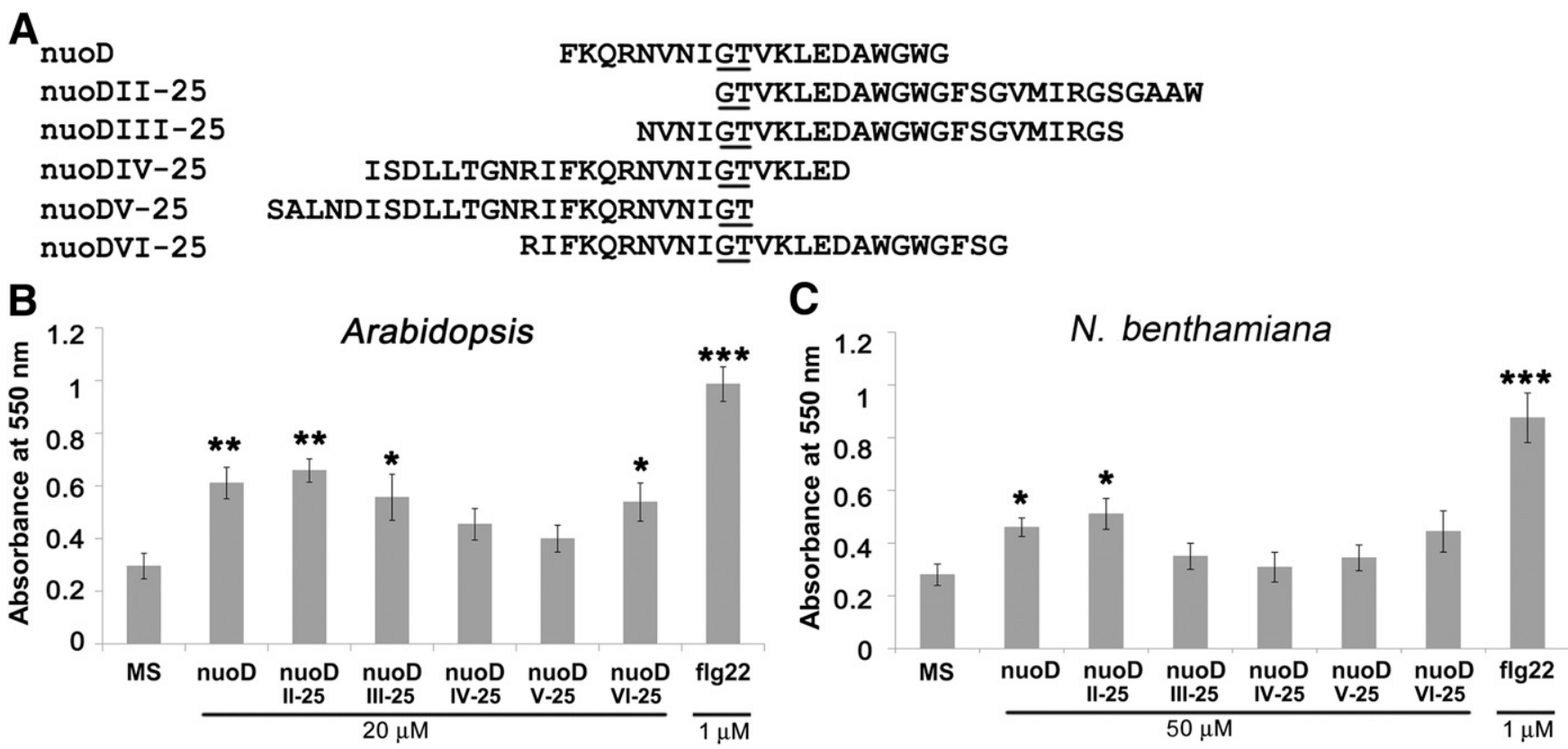

Fig. 3. nuoD variants exhibit different levels of reactive oxygen species production. A, nuoD variants with the positively selected "GT" sites (underlined), extended toward the $\mathrm{N}$ terminus or $\mathrm{C}$ terminus of the protein. B, Total peroxidase (POX) activity was measured after treatment with nuoD variants $(20 \mu \mathrm{M})$ in Arabidopsis. C, POX assay with nuoD variants $(50 \mu \mathrm{M})$ in Nicotiana benthamiana, as in part B. Data are shown as mean \pm standard deviation, $n=6$. Statistical significance was assessed by $t$ tests, where *, **, and $* * *$ indicate $P<0.05,0.01$, and 0.001 , respectively. Each experiment was repeated three times with similar results. 
sweet orange), or mixed reports of susceptibility (Kumquat, Kishu mandarin, and mandarinquat) (Bowman et al. 2016; Folimonova et al. 2009; McCollum et al. 2016). However, it should be noted that Eureka lemon and Mexican key lime have also been reported to be susceptible under field conditions
(Flores-Sánchez et al. 2017; Ramadugu et al. 2016). We first endeavored to establish POX and luminol assays in citrus in response to flg22 because it is a very strong MAMP. Despite multiple attempts, we were unable to see any activity in the POX assay with flg22 in citrus and, thus, focused on the
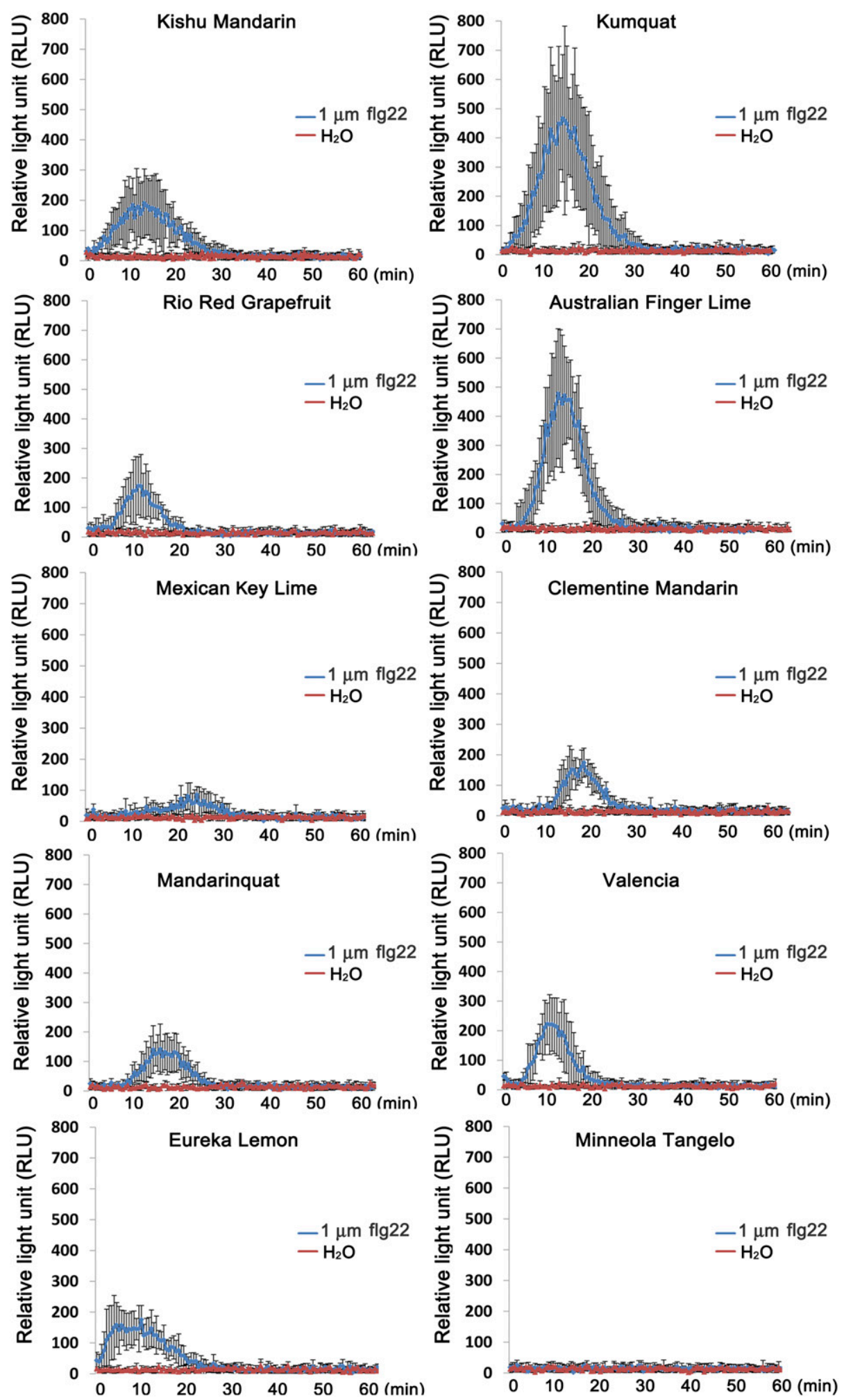

Fig. 4. Microbe-associated molecular pattern flg22 induced varying levels of reactive oxygen species (ROS) production in citrus species using the luminol assay. Luminol-based assay for flg22-triggered (blue) or water-induced (red) ROS production. The following citrus species were tested: Kishu mandarin, Kumquat, Rio Red grapefruit, Australian finger lime, Mexican key lime, clementine mandarin, mandarinquat, Valencia sweet orange, Eureka lemon, and Minneola tangelo. Relative light units (RLU) were monitored for $60 \mathrm{~min}$. The data are shown as mean \pm standard deviation, $n=6$. Each experiment was repeated three times with similar results. 
luminol assay. Using the luminol assay, we found that different citrus species varied in their ability to recognize flg22 and induce ROS production (Fig. 4; Supplementary Fig. S8). We observed high levels of ROS production (400 to 500 RLU) in kumquat and Australian finger lime and moderate ROS production (100 to 200 RLU) in Kishu mandarin, Rio Red grapefruit, Mexican key lime, clementine mandarin, mandarinquat, Valencia sweet orange, and Eureka lemon (Fig. 4; Supplementary Fig. S8). We were unable to detect any ROS production in Minneola tangelo. In most species, ROS production peaked at approximately 15 to $20 \mathrm{~min}$, except Mexican key lime, which peaked at $25 \mathrm{~min}$, and Minneola Tangelo, which did not respond.
We then tested our two best candidate MAMPs: nuoD (and the nuoDII-25 variant) and pksG. In Australian finger lime, Eureka lemon, and Kumquat, only pksG triggered responses that were stronger than or equal to the responses induced by flg22 in PBS-A buffer (Fig. 5). In the other citrus species, pksG did not trigger ROS production (Supplementary Fig. S9), and nuoD and nuoDII-25 did not trigger ROS production in any of the tested citrus species (Supplementary Fig. S10). To confirm these data and visualize the in situ accumulation of hydrogen peroxide $\left(\mathrm{H}_{2} \mathrm{O}_{2}\right)$, we employed nitroblue tetrazolium (NBT) staining in Australian finger lime and Minneola tangelo, because these two species displayed differing levels of ROS production. NBT precipitates in the presence of $\mathrm{H}_{2} \mathrm{O}_{2}$ and,
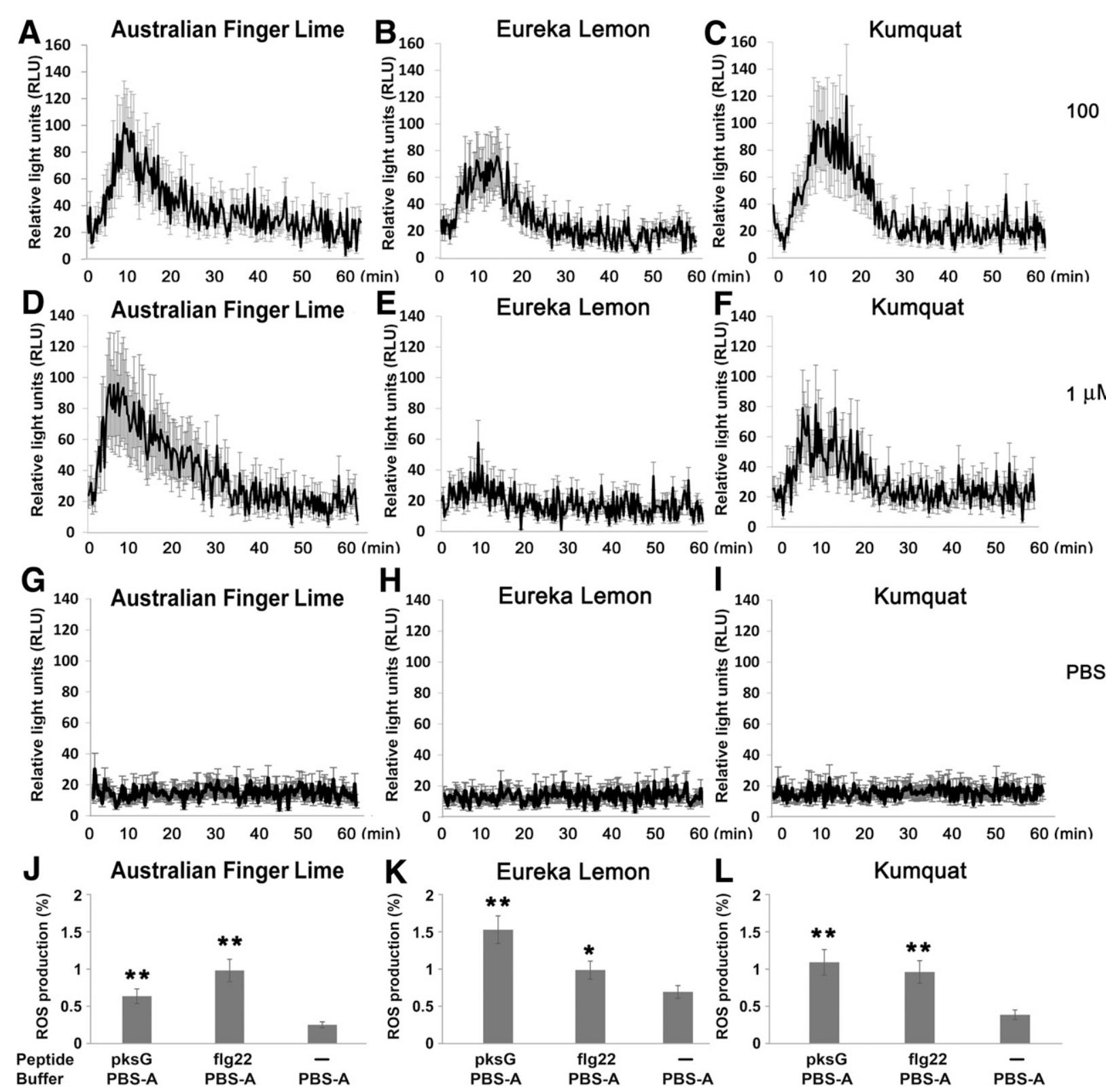

Fig. 5. pksG triggers varying levels of reactive oxygen species (ROS) production in citrus using the luminol assay. Luminol-based assay for pksG or flg22triggered ROS production. Relative light units (RLU) were monitored for $60 \mathrm{~min}$. Data are shown as mean \pm standard deviation, $n=6$. Each experiment was repeated three times with similar results. A, Australian finger lime, B, Eureka lemon, and C, Kumquat treated with $100 \mu \mathrm{M}$ pksG in phosphate-buffered saline amended with ammonium bicarbonate (PBS-A) buffer. D, Australian finger lime E, Eureka lemon, and F, Kumquat treated with $1 \mu$ M flg22 in PBS-A buffer. G, Australian finger lime $\mathbf{H}$, Eureka lemon, and I, Kumquat treated with PBS-A buffer. J, K, and $\mathbf{L}$, Total ROS production was calculated by integrating the area under the curve and normalizing the flg 22 treatment to $100 \%$. The average of four independent experiments is shown. Error bars represent standard error. Asterisks indicate statistically significant differences compared with the flg 22 treatment. Statistical significance was assessed by $t$ tests, where * and $* *$ indicate $P<0.05$ and 0.01 , respectively. 
therefore, should localize at the sites where $\mathrm{H}_{2} \mathrm{O}_{2}$ is generated (Wohlgemuth et al. 2002). We compared NBT staining $24 \mathrm{~h}$ after infiltration of pksG or flg22 into leaves. We observed strong NBT staining in Australian finger lime leaves infiltrated with flg22 (in $\mathrm{H}_{2} \mathrm{O}$ or PBS-A buffer) or pksG, and much weaker punctate staining in leaves infiltrated with $\mathrm{H}_{2} \mathrm{O}$, PBS-A buffer. or thrS peptide (Fig. 6A). Minneola tangelo displayed little NBT staining in response to flg22 or pksG treatment in PBS-A buffer, comparable with the $\mathrm{H}_{2} \mathrm{O}$, PBS-A buffer, or thrS peptide treatments (Fig. 6B). Quantification of NBT staining in three leaves through ImageJ analyses confirmed these results (Fig. 6C and D).

\section{pksG induces defense gene expression in citrus.}

To further demonstrate that MTI is induced, we analyzed the expression of selected defense genes after Australian finger lime or Minneola tangelo were treated with pksG or flg22. We selected MTI marker genes WRKY22 and GST1 and pathogenesis-related gene $P R I$ for expression analysis because these genes have previously been shown to be responsive to MAMP treatment in citrus (Shi et al. 2015, 2018). We carried out quantitative reverse-transcription PCR (qRT-PCR) to determine transcript abundance of WRKY22, GST1, and PRI. In Australian finger lime, $P R I$ gene expression decreased when treated with flg 22 for $24 \mathrm{~h}$ but was unaffected by pksG treatment (Fig. 7A). WRKY22 expression was strongly induced by pksG compared with flg22 (Fig. 7B). GST1 expression was unaffected after treatment with flg22 or pksG (Fig. 7C). As expected, based on our ROS assays (Fig. 6; Supplementary Fig. S9), no statistically significant differences in expression were observed for PR1, WRKY22, or GST1 marker genes in Minneola tangelo (Fig. 7D, E, and F).

pksG elicits immune responses to $P$. syringae.

$P$. syringae has been used to evaluate the effects of putative MAMPs on MTI (Hao et al. 2017; Lewis et al. 2015), because ' $C a$. L. asiaticus' disease symptoms take many years to develop in citrus. Therefore, to test whether pksG could elicit MTI, we carried out bacterial growth assays using the plant-pathogenic bacterium P. syringae pv. tomato DC3000 in Arabidopsis. We pretreated Arabidopsis with flg22 or pksG 1 day prior to infiltration with strain DC3000. In plants that were pretreated with $\mathrm{H}_{2} \mathrm{O}$ or PBS-A buffer, strain DC3000 grew to approximately $6.5 \operatorname{logs}$ after 2 days (Fig. 8). In plants that were pretreated with flg22 in water, strain DC3000 grew to approximately $1 \log$ less, to approximately $5.5 \operatorname{logs}$ (Fig. 8), as previously observed (Zeng et al. 2011). In plants that were pretreated with flg22 in PBS-A buffer or pksG in PBS-A buffer, strain DC3000 grew to approximately $0.5 \log$ less, to approximately 5.5 logs (Fig. 8). Therefore, pksG elicits a level of MTI response similar to that of flg22 in PBS-A buffer in Arabidopsis infected with $P$. syringae. This indicates that pksG can elicit MTI and protect plants against a pathogenic bacterium such as P. syringae.

\section{DISCUSSION}

HLB pathogens present many challenges because they are unculturable and cause devastating disease in citrus. Therefore, we pursued a comparative genomics approach to identify putative MAMPs in ' $C a$. Liberibacter' genomes. This strategy has been effective in identifying MAMPs in $P$. syringae and $R$. solanacearum (Eckshtain-Levi et al. 2018; McCann et al. 2012; Mott et al. 2016). From 13 candidate MAMPs, we identified 2 that trigger ROS production in Arabidopsis and N. benthamiana, and 1 of these also triggers ROS production in citrus. Our data suggest that evolutionary approaches may be effective strategies to identify MAMPs for crop protection.

The initial MAMP-induced ROS burst occurs in the apoplast and is a rapid and transient response (Baker and Orlandi 1995; Lamb and Dixon 1997). nuoD (and the nuoD variant nuoDII25) triggered the ROS burst in Arabidopsis and N. benthamiana

\section{A Australian Finger Lime}
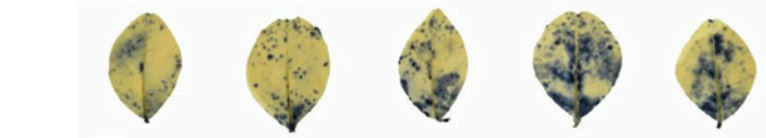

Peptide

Buffer
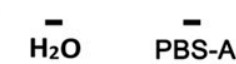

flg22

PBS-A

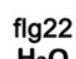

$\mathrm{H}_{2} \mathrm{O}$

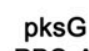

PBS-A
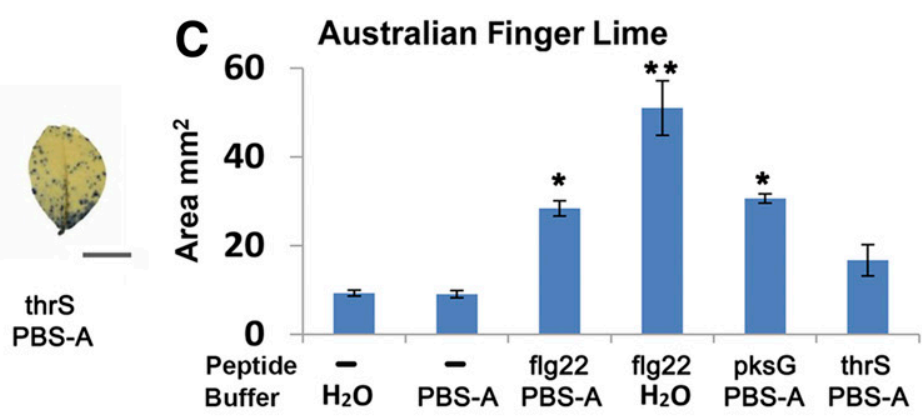

Australian Finger Lime

B Minneola Tangelo
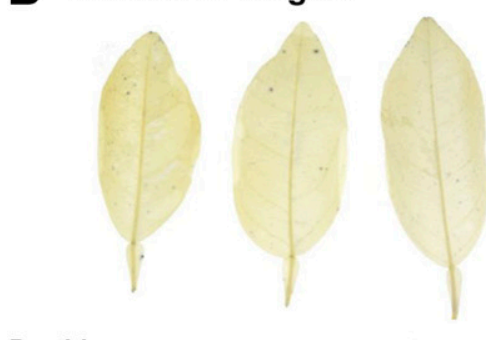

Peptide
Buffer $\quad \mathrm{H}_{2} \mathrm{O}$

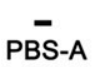

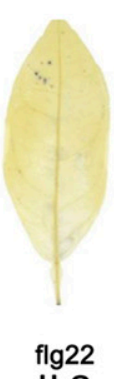

flg22
PBS-A

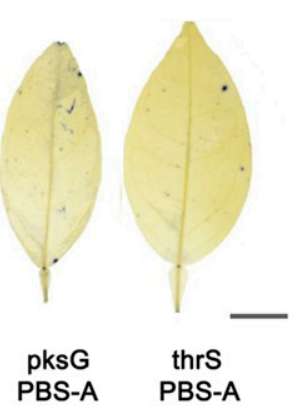

D

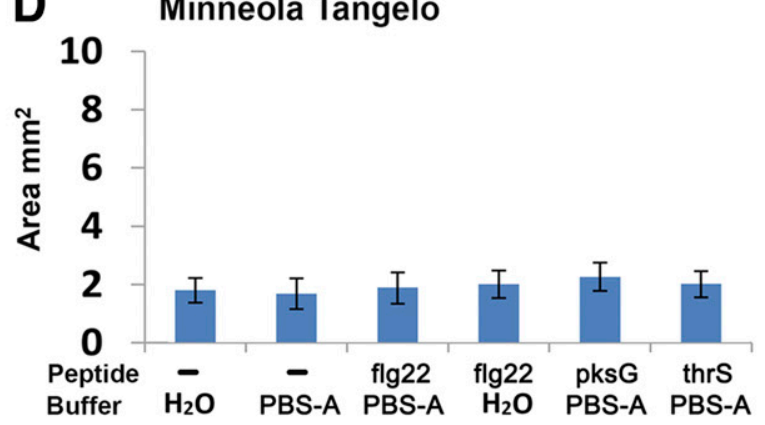

Fig. 6. Histochemical staining with nitroblue tetrazolium (NBT) for detection of in situ accumulation of hydrogen peroxide $\left(\mathrm{H}_{2} \mathrm{O}_{2}\right)$. Accumulation of $\mathrm{H}_{2} \mathrm{O}_{2}$ in citrus leaves, as detected by NBT staining. The dark blue color indicates strong $\mathrm{H}_{2} \mathrm{O}_{2}$ production. Leaves were treated with $\mathrm{H}_{2} \mathrm{O}$, phosphate-buffered saline amended with ammonium bicarbonate (PBS-A) buffer, $1 \mu \mathrm{M}$ flg22 in PBS-A buffer, $1 \mu \mathrm{M}$ flg2 22 in $\mathrm{H}_{2} \mathrm{O}, 100 \mu \mathrm{M}$ pksG in PBS-A buffer, or $100 \mu \mathrm{M}$ thrS in PBSA buffer. Representative leaves are shown from NBT staining after treatment in A, Australian finger lime or $\mathbf{B}$, Minneola tangelo. Scale bars indicates $1 \mathrm{~cm}$. $\mathbf{C}$ and $\mathbf{D}$, Quantification of the NBT-stained area as a proportion of the total leaf area from three leaves. 
(Figs. 1 and 3) but not in citrus (Supplementary Fig. S10). The full-length NuoD protein is a subunit of the NADH-quinone oxidoreductase complex that translocates protons for energy production as part of the respiratory chain (Sinha et al. 2015), and genes encoding the NADH-quinone oxidoreductase complex are widespread in bacteria (Degli Esposti 2015; Spero et al. 2015). NuoD is predicted to be localized to the plasma membrane. The nuoD peptide was clearly a much weaker inducer of MTI than flg22, which is known to be a highly potent MAMP. However, high concentrations of peptide were not sufficient to trigger MTI (Fig. 2), and our peptides were not contaminated with flg22 (Supplementary Fig. S4). For nuoD, the position of the positively selected sites affected the level of ROS production (Fig. 3). Extending the peptide toward the $\mathrm{N}$ terminus of the protein (i.e., in nuoDIV-25 or nuoDV-25) resulted in the loss of ROS production (Fig. 3). Because ROS production was restored in nuoD or nuoDVI-25, the GT sites could be more accessible in these peptides, or part of the $\mathrm{C}$-terminal region of the peptide might also contribute to MTI.

Our other MAMP, pksG, triggered the ROS burst in Arabidopsis, $N$. benthamiana, and citrus (Figs. 1, 2, and 5), and still elicited a response in the Ws ecotype of Arabidopsis that does not respond to flg22 (Supplementary Fig. S4). The pksG peptide is found in a polyketide synthase, which is a class of enzymes producing medicinally important secondary metabolites that can also contribute to bacterial communication (Palazzotto and Weber 2018). PksG is functionally annotated as a hydroxymethylglutaryl-CoA synthase, and has been found in diverse bacteria and archaea (Calderone et al. 2006; Makarova and Koonin 2003; Piel et al. 2004). The PksG protein is predicted to be present in the cytoplasm; thus, the peptide might be exposed as bacterial populations turn over. Due to the hydrophobicity of pksG, we found that a basic PBS buffer (PBS-A) was critical for its solubilization. Interestingly, in the PBS-A buffer, pksG could induce levels of ROS production similar to that of flg22, at low peptide concentrations $(5 \mu \mathrm{M}$ for $\mathrm{pksG}$ versus $1 \mu \mathrm{M}$ for flg22) (Fig. 1). We infer that less pksG peptide was sufficient to elicit a response in PBS-A buffer because it was more soluble in this buffer compared than in $\mathrm{H}_{2} \mathrm{O}$. It is unclear whether the pksG epitope would be exposed in planta, because it would depend on the threedimensional folding of the full protein, and the plant environment is acidic.

We found that flg22 could trigger a second long-lasting ROS burst 2 to $5 \mathrm{~h}$ after MAMP treatment in $N$. benthamiana but not in Arabidopsis (Supplementary Fig. S6A). The biphasic accumulation of ROS has been known for many years (Atkinson et al. 1990; Keppler et al. 1989), and occurs in

\section{Australian Finger Lime}
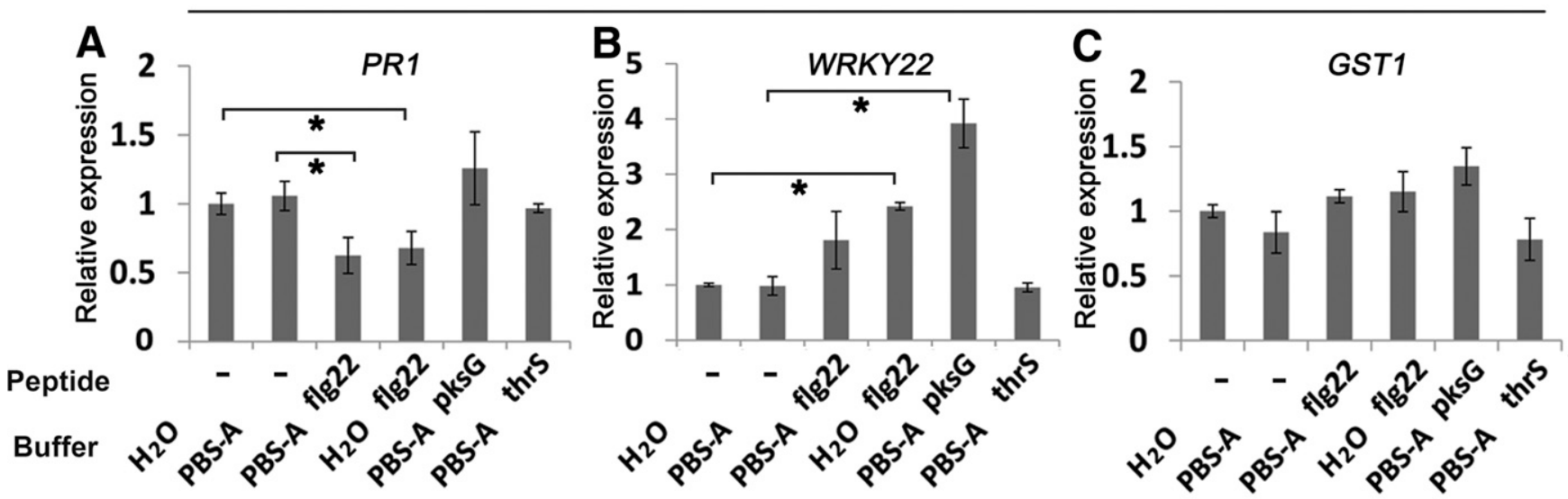

Minneola Tangelo
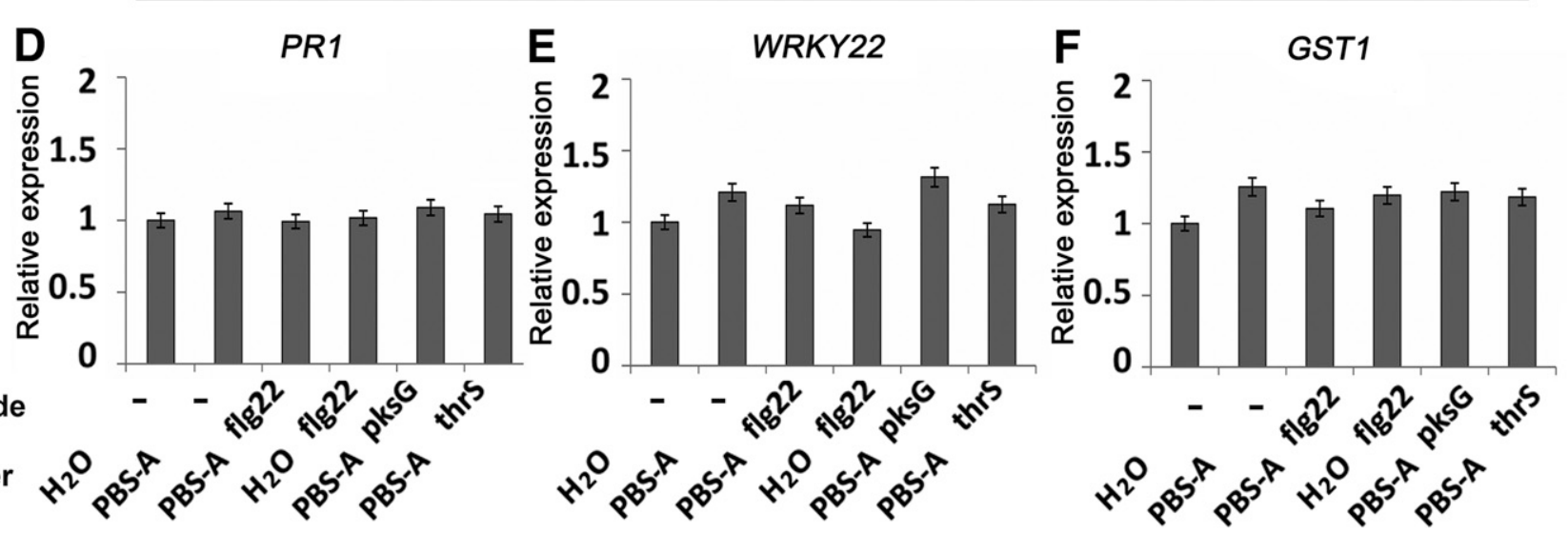

Fig. 7. Responses of defense-associated genes in huanglongbing (HLB)-tolerant and susceptible cultivars. A to C, Australian finger lime or D to F, Minneola tangelo were infiltrated with $\mathrm{H}_{2} \mathrm{O}$, phosphate-buffered saline amended with ammonium bicarbonate (PBS-A) buffer, $1 \mu \mathrm{M}$ flg22 in PBS-A buffer, $1 \mu \mathrm{M}$ flg22 in $\mathrm{H}_{2} \mathrm{O}, 100 \mu \mathrm{M}$ pksG in PBS-A buffer, or $100 \mu \mathrm{M}$ thrS in PBS-A buffer. Microbe-associated molecular pattern-triggered immunity (MTI) marker gene expression was evaluated $24 \mathrm{~h}$ postinfiltration, and quantified by quantitative reverse-transcription PCR with gene-specific primers. PR1, WRKY22, and GST1 were selected as MTI marker genes, and GAPC2 was used as the reference gene (Mafra et al. 2013). An asterisk indicates significant differences $(P<0.05)$ between the treatment and control. Bars are means \pm standard deviation. Data are shown from three biological replicates. 
Arabidopsis in response to lipopolysaccharide treatment (Shang-Guan et al. 2018). However, none of our candidate MAMPs induced the second ROS burst in $N$. benthamiana (Supplementary Fig. S7).

We employed flg22 from $P$. aeruginosa as a strong positive control for MTI responses, because it is the standard MAMP in the field. Using flg22, we established luminol assays for ROS production in citrus species, which will be a useful tool for future research (Fig. 4; Supplementary Fig. S8). flg22 triggered different levels of ROS production in citrus species (Fig. 4; Supplementary Fig. S8). The ROS bursts in citrus species varied from 150 to 400 RLU, which is lower than that observed in other plants such as Arabidopsis and $N$. benthamiana. However, similar levels of ROS production have previously been observed in citrus species (Pitino et al. 2015; Shi et al. 2015). Recent transcriptomic studies demonstrated that genes involved in biotic stress and signaling were upregulated in HLB-tolerant citrus compared with HLB-susceptible citrus (Shi et al. 2018; Wang et al. 2016; Yu et al. 2017), suggesting that immunity is enhanced in HLB-tolerant varieties. However, we found that there was not a strong correlation between flg22-triggered ROS production and responses in cultivars that are purported to be resistant or tolerant to HLB. Although pksG exhibited similar or stronger ROS production compared with that induced by flg22 (Figs. 4, 5, and 6), pksG and flg22 treatment resulted in different effects on MTI marker gene expression (Fig. 7). As previously observed in HLB or citrus canker-tolerant varieties (Pitino et al. 2015; Shi et al. 2015, 2018), flg22 treatment resulted in reduced $P R 1$ gene expression compared with the buffer controls (Fig. 7). These effects were specific to Australian finger lime because pksG and flg22 did not result in NBT staining in Minneola tangelo (Fig. 6). In addition, neither peptide caused differential MTI marker gene expression (Fig. 7) in Minneola tangelo. pksG treatment resulted in greater WRKY22 expression in Australian finger lime compared with Minneola tangelo (Fig. 7). Yu and colleagues (2017) demonstrated

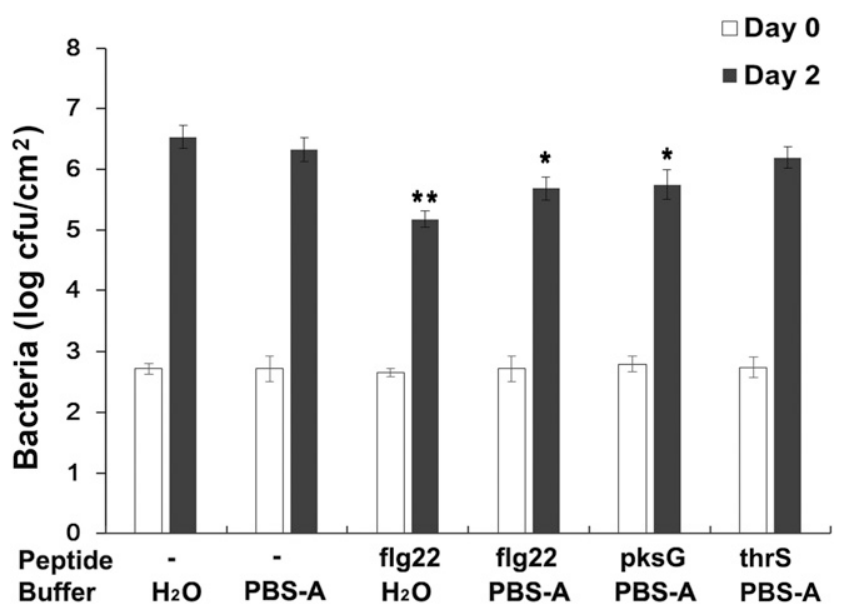

Fig. 8. Pretreatment with pksG induces microbe-associated molecular pattern-triggered immunity to Pseudomonas syringae in Arabidopsis. $\mathrm{H}_{2} \mathrm{O}$, phosphate-buffered saline amended with ammonium bicarbonate (PBS-A) buffer, $10 \mu \mathrm{M}$ pksG (in PBS-A buffer), or $1 \mu \mathrm{M}$ flg22 (in $\mathrm{H}_{2} \mathrm{O}$ or PBS-A buffer) were infiltrated into leaves of 5-week-old Arabidopsis plants with a needleless syringe. After $24 \mathrm{~h}$, the same leaves were syringe infiltrated with P. syringae pv. tomato DC3000 at $1 \times 10^{5} \mathrm{CFU} / \mathrm{ml}$. Bacterial growth was determined at $1 \mathrm{~h}$ (Day 0) and 2 days (Day 2) postinoculation. The log average of six individuals is shown. Error bars represent standard error. Asterisks indicate statistically significant differences compared with the appropriate buffer control. Statistical significance was assessed by $t$ tests, where $*$ and $* *$ indicate $P<0.05$ and 0.01 , respectively. that $W R K Y$ genes were differentially expressed in HLB-tolerant rough lemon compared with HLB-susceptible sweet orange in an RNA sequencing experiment in ' $\mathrm{Ca}$. L. asiaticus'-infected citrus. WRKY genes can connect microbe-associated molecular pattern perception to defense gene expression and hormone regulation, and affect disease outcomes (Eulgem and Somssich 2007). Although we were unable to test for the effect of pksG on ' $\mathrm{Ca}$. L. asiaticus' infection due to the very lengthy timescales necessary for disease, we demonstrated that pksG can induce MTI and reduce growth of $P$. syringae in Arabidopsis (Fig. 8), which further supports that it is a bona fide MAMP. Our data suggest that specific species of citrus may recognize pksG and flg22 by different mechanisms. Other studies have shown that MAMPs can have differing effects on $\mathrm{Ca}^{2+}$ influx and gene expression (Aslam et al. 2009; Lecourieux et al. 2005; Segonzac et al. 2011). In addition, after MAMP perception and $\mathrm{Ca}^{2+}$ influx, parallel signaling pathways in $N$. benthamiana trigger the ROS burst versus MAPK activation and MAMPinduced gene expression (Segonzac et al. 2011).

Genome sequence analysis indicates that ' $\mathrm{Ca}$. L. asiaticus' encodes most flagellar genes which could function as MAMPs (Bendix and Lewis 2018; Wang et al. 2017; Zou et al. 2012;). Indeed, flg22 from ' $C a$. L. asiaticus' has been shown to act as a weak MAMP in citrus (Shi et al. 2018) compared with flg 22 from $X$. citri pv. citri, which causes citrus canker (Shi et al. 2015). 'Ca. L. asiaticus' flg22 triggers rapid ROS production and induces the expression of MTI marker genes in moderately HLB-tolerant species (Shi et al. 2015, 2018; Zou et al. 2012). However, it is not clear which PRR recognizes ' $C a$. L. asiaticus' flg 22 because PRRs are not well characterized in citrus. Transient expression of citrus FLS2 from resistant Nagami kumquat (FmFLS2-1) or Sun Chu Sha mandarin (CrFLS2-2) was able to enhance MTI, suggesting that these proteins may function as flagellin receptors in citrus (Shi et al. 2016). Transcriptional analysis has shown that an LysM RLK (CHITIN ELICITOR RECEPTOR KINASE 1) and other RLKs are induced in ' $\mathrm{Ca}$. L. asiaticus'-infected plants (Aritua et al. 2013; Mafra et al. 2013). However, it is unknown whether these act as PRRs. An open question is how the perception of the MAMP could occur at the surface of the cell membrane, when the bacterium is present in intracellular spaces. Under natural conditions, MTI is not effective in preventing ' $\mathrm{Ca}$. L. asiaticus' infection, perhaps because its effectors overcome MTI (Clark et al. 2018), as has been seen for other plant pathogens (Block and Alfano 2011; Lewis et al. 2009; Wang et al. 2017). Alternatively, perhaps MTI is not induced due to the low titer of ' $C a$. L. asiaticus', which might keep MAMPs at a very low level (Selvaraj et al. 2018), or its phloem niche, which might restrict the recognition of MAMPs by PRRs (Aslam et al. 2009). Our data demonstrate that specific MAMPs can stimulate significant immune responses. If these MAMPs are delivered in sufficient quantity to the right tissues, this could result in stronger MTI that might be sufficient to limit infection.

Our data show that nuoD induces ROS production and pksG induces MTI at a very early step of the signaling cascade. Fragments of flagellin and other MAMPs have been successfully used to enhance resistance in crops such as tobacco, wheat, sunflower, beet, rice, and tomato (Hao et al. 2014; Nandeeshkumar et al. 2008; Quintana-Rodriguez et al. 2018). Expression of candidate MAMPs under pathogeninduced phloem-specific promoters could be a means to trigger strong MTI after perception of the pathogen. This approach combined with new MAMPs could be used as a means to boost immunity in citrus and to prevent HLB infection. 


\section{MATERIALS AND METHODS}

Plant materials and growth conditions.

Arabidopsis plants (Col-0 ecotype and Ws ecotype) were grown in a growth chamber at $22^{\circ} \mathrm{C}$ with cycles of $9 \mathrm{~h}$ of light $(130 \mu \mathrm{E}$ $\mathrm{m}^{-2} \mathrm{~s}^{-1}$ ) and $15 \mathrm{~h}$ of darkness. $N$. benthamiana plants were grown at $22^{\circ} \mathrm{C}$ with cycles of $14 \mathrm{~h}$ of light $\left(150 \mu \mathrm{E} \mathrm{m} \mathrm{m}^{-2} \mathrm{~s}^{-1}\right)$ and $10 \mathrm{~h}$ of darkness. Three-year-old citrus plants (from Four Winds Growers) were grown in a greenhouse at $23^{\circ} \mathrm{C}$. Mexican key lime, Australian finger lime, Eureka lemon, Clementine mandarin, Minneola tangelo, Rio Red grapefruit, Valencia sweet orange, Kumquat, Kishu mandarin, and mandarinquat plants were pruned to encourage new flush and young, fully expanded leaves were used for luminol-based plate assays.

\section{Core-genome prediction and selection analysis.}

The analysis was performed using sequences from ' $\mathrm{Ca}$. L. asiaticus', ' $C a$. L. americanus', ' $C a$. L. africanus', ' $C a$. L. solanacearum', and a nonpathogenic relative, L. crescens (Fagen et al. 2014; Naranjo et al. 2019). The ' $\mathrm{Ca}$. L. asiaticus' strains were gxpsy (GCF_000346595.1), psy62 (GCF_000023765.2), A4 (GCF_000590865.2), Ishi-1 (GCF_000829355.1), HHCA (GCF_000724755.2), FL17 (GCF_000820625.1), and YCPsy (GCF_001296945.1). The 'Ca. L. americanus' strains were PW-SP (GCF_000350385.1) and Sao Paulo (GCF_000496595.1). The 'Ca. L. africanus' strain was PTSAPSY (GCF_001021085). The ‘Ca. L. solanacearum' strains were Clso-ZC1 (GCF_000183665.1), R1 (GCF_000756225.1), HenneA (GCF_000968075.1), LsoNZ1 (GCF_000968085.1), and RSTM (GCF_001414235.1). The L. crescens strains were BT-0 (GCF_001543305.1) and BT-1 (GCF_000325745.1). Prokka was used to annotate the genomes and produce GFF3 files (Seemann 2014). These files were used as input for Roary to identify core and accessory genes in the pan-genome from related species (Page et al. 2015). Core gene sets were first generated at $95 \%$ Blastp cutoff for each species: 'Ca. L. asiaticus', 'Ca. L. americanus', ' $C a$. L. africanus', ' $C a$. L. solanacearum', or L. crescens. Roary uses the blast results as input to the Markov Cluster algorithm, which clusters related proteins, to identify homologous genes (Enright et al. 2002; Page et al. 2015). Selection analysis was performed using the codeml program in the PAML 4.8 application suite. The core genome alignment and tree produced by Roary were used as input files. The program ete evol was used to run codeml on the full core genomes. The codeml models M1 versus M2 or M7 versus M8 were compared using likelihood ratio tests in order to identify positive selection on sites. Bayes Empirical Bayes estimates with a posterior probability of $>0.5$ from the positive selection models M2 and M8 were used to identify positively selected sites.

After positively selected codons were identified, Artemis was used to identify which ' $C a$. L. asiaticus' genes were under selection. These genes were compiled into a list and organized according to how many positive selection sites were present in each. In addition, the selection sites were evaluated for their proximity to gaps and stop codons in the sequence; those closer to such sites were considered less reliable. The strongest candidates were those with a higher number of reliable positive selection sites. To refine the list of candidates in ' $\mathrm{Ca}$. L. asiaticus' under positive selection, a second round of analysis was carried out to identify new core gene sets for different groupings of ' $\mathrm{Ca}$. L. asiaticus' with the related species. These groupings were ' $C a$. L. asiaticus' and ' $C a$. L. americanus', ' $C a$. L. asiaticus' and 'Ca. L. africanus', 'Ca. L. asiaticus' and 'Ca. L. solanacearum', or 'Ca. L. asiaticus' and L. crescens, with $80 \%$ Blastp cutoff.

\section{Peptides.}

The predicted MAMPs were designed from the ' $\mathrm{Ca}$. Liberibacter' genome sequences. The peptides were designed to encompass the positively selected sites and to include more antigenic regions of the proteins as predicted by the Kolaskar-Tongaonkar method in CLC Bio, version 6.9.1 (Kolaskar and Tongaonkar 1990). The flg22 sequence (QRLSTGSRINSAKDDAAGLQIA) is from the $P$. aeruginosa genome, and is standardly used as a strong positive control for MTI. All peptides at $>95 \%$ purity were purchased from the Bio Basic Inc. or Biomer Technology LLC. All peptides except pksG were dissolved in water, because they were highly soluble in water. Because pksG was not soluble in water, it was dissolved in PBS-A buffer as a $400 \mu \mathrm{M}$ stock solution and sonicated for $5 \mathrm{~min}$ (20 s of sonication and $30 \mathrm{~s}$ of break). PBS-A buffer was composed of PBS buffer at $\mathrm{pH} 7.4$ supplemented with $0.2 \mathrm{mM}$ $\mathrm{NH}_{4} \mathrm{HCO}_{3}$ as a $1: 1$ mixture. pksG working solutions (5 and $100 \mu \mathrm{M})$ were diluted from the stock solution with distilled $\mathrm{H}_{2} \mathrm{O}$.

\section{ROS production assays.}

The POX assay in Arabidopsis and N. benthamiana was performed as previously described (Mott et al. 2016). In brief, leaf disks ( $5 \mathrm{~mm}$ in diameter) were obtained from young leaves by coring and incubated with $50 \mu \mathrm{l}$ of $1 \times$ MS buffer alone or supplemented with different peptides in a 96-well plate. After a $20-\mathrm{h}$ incubation, the leaf disks were removed and each well received $50 \mu \mathrm{l}$ of a $1-\mathrm{mg} / \mathrm{ml}$ solution of 5-aminosalicylic acid (A79809; Sigma-Aldrich), $\mathrm{pH}$ 6.0, with $0.01 \% \mathrm{H}_{2} \mathrm{O}_{2}$. The reaction was allowed to proceed for $3 \mathrm{~min}$ and stopped by the addition of $2 \mathrm{~N}$ $\mathrm{NaOH}$ prior to reading the optical density at $600 \mathrm{~nm}$ on a Tecan Spark $10 \mathrm{M}$ plate reader. The luminol assay was performed as previously described (Baker and Mock 2004). In brief, leaf disks ( $5 \mathrm{~mm}$ in diameter) were obtained from young leaves by coring and incubated overnight in a 96-well plate with water. The following day, $200 \mu \mathrm{M}$ luminol, horseradish POX at $20 \mu \mathrm{g} / \mathrm{ml}$, and peptides were added to each well. Isoluminol $(600 \mu \mathrm{M})$ was used to achieve a similar magnitude for the flg22-triggered apoplastic ROS burst. Luminescence was measured using the Tecan Spark $10 \mathrm{M}$ plate reader.

\section{Histochemical staining of ROS.}

Peptides, distilled water, or buffer were infiltrated into the abaxial surface of the leaf using a 1-ml needleless syringe. Infiltrated leaves were detached and placed in freshly prepared NBT solutions at $1 \mathrm{mg} / \mathrm{ml}$, followed by vacuum infiltration for $2 \mathrm{~h}$ and incubation in the dark for $24 \mathrm{~h}$ at $28^{\circ} \mathrm{C}$ with shaking. The leaves were cleared by boiling in $95 \%$ ethanol for $30 \mathrm{~min}$ and kept in $75 \%$ ethanol for 5 to 7 days until cleared.

\section{qRT-PCR.}

Peptides were infiltrated into the abaxial surface of the leaf using a 1-ml needleless syringe. Leaf tissue was collected $24 \mathrm{~h}$ after infiltration and RNA was extracted from infiltrated areas using the RNeasy plant mini kit (Qiagen). cDNA was synthesized as previously described (Chen et al. 2016). qRT-PCR was performed using CFX96 real-time PCR detection system (Bio-Rad) with SYBR Green PCR Master Mix. The thermocycler program was as follows: $95^{\circ} \mathrm{C}$ for 30 $\mathrm{s}$, followed by 40 cycles alternating between $5 \mathrm{~s}$ at $95^{\circ} \mathrm{C}$ and $15 \mathrm{~s}$ at $60^{\circ} \mathrm{C}$. Three biological replicates were performed for each sample. The primers are shown in Supplementary Table S2.

\section{Induced resistance assays.}

Induced resistance assays were performed as previously described (Boutrot et al. 2010). Briefly, $\mathrm{H}_{2} \mathrm{O}$, PBS-A buffer, $10 \mu \mathrm{M}$ pksG (in PBS-A buffer), or $1 \mu \mathrm{M}$ flg22 (in $\mathrm{H}_{2} \mathrm{O}$ or PBS-A buffer) were infiltrated into leaves of 5-week-old Arabidopsis plants with a needleless syringe. After $24 \mathrm{~h}$, the same leaves were 
syringe infiltrated with $P$. syringae pv. tomato DC3000 at $1 \times 10^{5}$ $\mathrm{CFU} / \mathrm{ml}$. Bacterial growth was determined 2 days postinoculation by harvesting four disks ( $1 \mathrm{~cm}^{2}$ each) of tissue, grinding in $10 \mathrm{mM}$ $\mathrm{MgCl}_{2}$, and plating on King's $\mathrm{B}$ medium with rifampicin and cycloheximide, as previously described (Lewis et al. 2008).

\section{Statistical analysis.}

The data were analyzed with a one-way analysis of variance at a significance level of $P<0.05$ followed by a multiple comparisons of means using Tukey's post hoc test. Error bars indicate standard deviation. Data were statistically analyzed using GraphPad Prism 8 software.

\section{ACKNOWLEDGMENTS}

We thank K. Schreiber and M. Baudin for constructive feedback on the manuscript; and Plant Gene Expression Center greenhouse staff L. Poasa J. Calfas, S. Kelley, and C. Tucker for assistance with citrus plants.

\section{AUTHOR-RECOMMENDED INTERNET RESOURCES}

ete evol: http://etetoolkit.org/documentation/ete-evol/

Artemis: https://www.sanger.ac.uk/science/tools/artemis

\section{LITERATURE CITED}

Aritua, V., Achor, D., Gmitter, F. G., Albrigo, G., and Wang, N. 2013. Transcriptional and microscopic analyses of citrus stem and root responses to Candidatus Liberibacter asiaticus infection. PLoS One 8:e73742.

Aslam, S. N., Erbs, G., Morrissey, K. L., Newman, M. A., Chinchilla, D., Boller, T., Molinaro, A., Jackson, R. W., and Cooper, R. M. 2009. Microbe-associated molecular pattern (MAMP) signatures, synergy, size and charge: Influences on perception or mobility and host defence responses. Mol. Plant Pathol. 10:375-387.

Atkinson, M. M., Keppler, L. D., Orlandi, E. W., Baker, C. J., and Mischke, C. F. 1990. Involvement of plasma membrane calcium influx in bacterial induction of the $\mathrm{K}^{+} / \mathrm{H}^{+}$and hypersensitive responses in tobacco. Plant Physiol. 92:215-221.

Baker, C. J., and Mock, N. M. 2004. A method to detect oxidative stress by monitoring changes in the extracellular antioxidant capacity in plant suspension cells. Physiol. Mol. Plant Pathol. 64:255-261.

Baker, C. J., and Orlandi, E. W. 1995. Active oxygen in plant pathogenesis. Annu. Rev. Phytopathol. 33:299-321.

Bendix, C., and Lewis, J. D. 2018. The enemy within: Phloem-limited pathogens. Mol. Plant Pathol. 19:238-254.

Block, A., and Alfano, J. R. 2011. Plant targets for Pseudomonas syringae type III effectors: Virulence targets or guarded decoys? Curr. Opin. Microbiol. 14:39-46

Boller, T., and Felix, G. 2009. A renaissance of elicitors: Perception of microbe-associated molecular patterns and danger signals by patternrecognition receptors. Annu. Rev. Plant Biol. 60:379-406.

Boutrot, F., Segonzac, C., Chang, K. N., Qiao, H., Ecker, J. R., Zipfel, C., and Rathjen, J. P. 2010. Direct transcriptional control of the Arabidopsis immune receptor FLS2 by the ethylene-dependent transcription factors EIN3 and EIL1. Proc. Natl. Acad. Sci. U.S.A. 107:14502-14507.

Bové, J. M. 2006. Huanglongbing: A destructive, newly-emerging, centuryold disease of citrus. J. Plant Pathol. 88:7-37.

Bowman, K. D., McCollum, G., and Albrecht, U. 2016. Performance of 'Valencia' orange (Citrus sinensis [L.] Osbeck) on 17 rootstocks in a trial severely affected by Huanglongbing. Sci. Hortic. 201:355-361.

Calderone, C. T., Kowtoniuk, W. E., Kelleher, N. L., Walsh, C. T., and Dorrestein, P. C. 2006. Convergence of isoprene and polyketide biosynthetic machinery: Isoprenyl-S-carrier proteins in the $p k s X$ pathway of Bacillus subtilis. Proc. Natl. Acad. Sci. U.S.A. 103:8977-8982.

Camejo, D., Guzmán-Cedeño, Á., and Moreno, A. 2016. Reactive oxygen species, essential molecules, during plant-pathogen interactions. Plant Physiol. Biochem. 103:10-23.

Canales, E., Coll, Y., Hernández, I., Portieles, R., Rodríguez García, M., López, Y., Aranguren, M., Alonso, E., Delgado, R., Luis, M., Batista, L., Paredes, C., Rodríguez, M., Pujol, M., Ochagavia, M. E., Falcón, V., Terauchi, R., Matsumura, H., Ayra-Pardo, C., Llauger, R., Pérez, M. C., Núñez, M., Borrusch, M. S., Walton, J. D., Silva, Y., Pimentel, E., Borroto, C., and Borrás-Hidalgo, O. 2016. 'Candidatus Liberibacter asiaticus', causal agent of citrus Huanglongbing, is reduced by treatment with brassinosteroids. PLoS One 11:e0146223.

Chen, Y., Zou, T., and McCormick, S. 2016. S-adenosylmethionine synthetase 3 is important for pollen tube growth. Plant Physiol. 172:244-253.

Clark, K., Franco, J. Y., Schwizer, S., Pang, Z., Hawara, E., Liebrand, T. W. H., Pagliaccia, D., Zeng, L., Gurung, F. B., Wang, P., Shi, J., Wang, Y., Ancona, V., van der Hoorn, R. A. L., Wang, N., Coaker, G., and Ma, W. 2018. An effector from the Huanglongbing-associated pathogen targets citrus proteases. Nat. Commun. 9:1718.

da Graça, J. V., Douhan, G. W., Halbert, S. E., Keremane, M. L., Lee, R. F., Vidalakis, G., and Zhao, H. 2016. Huanglongbing: An overview of a complex pathosystem ravaging the world's citrus. J. Integr. Plant Biol 58:373-387.

Daudi, A., Cheng, Z., O’Brien, J. A., Mammarella, N., Khan, S., Ausubel, F. M., and Bolwell, G. P. 2012. The apoplastic oxidative burst peroxidase in Arabidopsis is a major component of pattern-triggered immunity. Plant Cell 24:275-287.

Degli Esposti, M. 2015. Genome analysis of structure-function relationships in respiratory complex I, an ancient bioenergetics enzyme. Genome Biol. Evol. 8:126-147.

Eckshtain-Levi, N., Weisberg, A. J., and Vinatzer, B. A. 2018. The population genetic test Tajima's D identifies genes encoding pathogenassociated molecular patterns and other virulence-related genes in Ralstonia solanacearum. Mol. Plant Pathol. 19:2187-2192.

Enright, A. J., Van Dongen, S., and Ouzounis, C. A. 2002. An efficient algorithm for large-scale detection of protein families. Nucleic Acids Res. 30:1575-1584.

Eulgem, T., and Somssich, I. E. 2007. Networks of WRKY transcription factors in defense signaling. Curr. Opin. Plant Biol. 10:366-371.

Fagen, J. R., Leonard, M. T., Coyle, J. F., McCullough, C. M., DavisRichardson, A. G., Davis, M. J., and Triplett, E. W. 2014. Liberibacter crescens gen. nov., sp. nov., the first cultured member of the genus Liberibacter. Int. J. Syst. Evol. Microbiol. 64:2461-2466.

Felix, G., Duran, J. D., Volko, S., and Boller, T. 1999. Plants have a sensitive perception system for the most conserved domain of bacterial flagellin. Plant J. 18:265-276.

Flores-Sánchez, J. L., Mora-Aguilera, G., Loeza-Kuk, E., López-Arroyo, J. I., Gutiérrez-Espinosa, M. A., Velázquez-Monreal, J. J., DomínguezMonge, S., Bassanezi, R. B., Acevedo-Sánchez, G., and Robles-García, P. 2017. Diffusion model for describing the regional spread of Huanglongbing from first-reported outbreaks and basing an area wide disease management strategy. Plant Dis. 101:1119-1127.

Folimonova, S. Y., Robertson, C. J., Garnsey, S. M., Gowda, S., and Dawson, W. O. 2009. Examination of the responses of different genotypes of citrus to huanglongbing (citrus greening) under different conditions. Phytopathology 99:1346-1354.

Gómez-Gómez, L., and Boller, T. 2000. FLS2: An LRR receptor-like kinase involved in the perception of the bacterial elicitor flagellin in Arabidopsis. Mol. Cell 5:1003-1011.

Gottwald, T. R. 2010. Current epidemiological understanding of citrus Huanglongbing. Annu. Rev. Phytopathol. 48:119-139.

Gust, A. A., Biswas, R., Lenz, H. D., Rauhut, T., Ranf, S., Kemmerling, B., Götz, F., Glawischnig, E., Lee, J., Felix, G., and Nürnberger, T. 2007 Bacteria-derived peptidoglycans constitute pathogen-associated molecular patterns triggering innate immunity in Arabidopsis. J. Biol. Chem. 282:32338-32348.

Hao, G., Pitino, M., Ding, F., Lin, H., Stover, E., and Duan, Y. 2014 Induction of innate immune responses by flagellin from the intracellular bacterium, 'Candidatus Liberibacter solanacearum'. BMC Plant Biol. 14:211.

Hao, G., Zhang, S., and Stover, E. 2017. Transgenic expression of antimicrobial peptide D2A21 confers resistance to diseases incited by Pseudomonas syringae pv. tabaci and Xanthomonas citri, but not Candidatus Liberibacter asiaticus. PLoS One 19:e0186810.

Heath, M. C. 2000. Hypersensitive response-related death. Plant Mol. Biol. 44:321-334.

Hoffman, M. T., Doud, M. S., Williams, L., Zhang, M. Q., Ding, F., Stover, E., Hall, D., Zhang, S., Jones, L., Gooch, M., Fleites, L., Dixon, W., Gabriel, D., and Duan, Y. P. 2013. Heat treatment eliminates 'Candidatus Liberibacter asiaticus' from infected citrus trees under controlled conditions. Phytopathology 103:15-22

Jones, J. D., and Dangl, J. L. 2006. The plant immune system. Nature 444 323-329.

Kacar, B., Garmendia, E., Tuncbag, N., Andersson, D. I., and Hughes, D. 2017. Functional constraints on replacing an essential gene with its ancient and modern homologs. MBio 8:e01276-17.

Keppler, L. D., Baker, C. J., and Atkinson, M. M. 1989. Active oxygen production during a bacteria-induced hypersensitive reaction in tobacco suspension cells. Phytopathology 79:974-978. 
Kolaskar, A. S., and Tongaonkar, P. C. 1990. A semi-empirical method for prediction of antigenic determinants on protein antigens. FEBS Lett. 276:172-174.

Kunze, G., Zipfel, C., Robatzek, S., Niehaus, K., Boller, T., and Felix, G. 2004. The $\mathrm{N}$ terminus of bacterial elongation factor Tu elicits innate immunity in Arabidopsis plants. Plant Cell 16:3496-3507.

Lacombe, S., Rougon-Cardoso, A., Sherwood, E., Peeters, N., Dahlbeck, D., van Esse, H. P., Smoker, M., Rallapalli, G., Thomma, B., Staskawicz, B. J. Jones, J. D. G., and Zipfel, C. 2010. Interfamily transfer of a plant pattern-recognition receptor confers broad-spectrum bacterial resistance. Nat. Biotechnol 28:365-U94.

Lamb, C., and Dixon, R. A. 1997. The oxidative burst in plant disease resistance. Annu. Rev. Plant Physiol. Plant Mol. Biol. 48:251-275.

Lecourieux, D., Lamotte, O., Bourque, S., Wendehenne, D., Mazars, C., Ranjeva, R., and Pugin, A. 2005. Proteinaceous and oligosaccharidic elicitors induce different calcium signatures in the nucleus of tobacco cells. Cell Calcium 38:527-538.

Lewis, J. D., Abada, W., Ma, W. B., Guttman, D. S., and Desveaux, D. 2008. The HopZ family of Pseudomonas syringae type III effectors require myristoylation for virulence and avirulence functions in Arabidopsis thaliana. J. Bacteriol. 190:2880-2891.

Lewis, J. D., Guttman, D. S., and Desveaux, D. 2009. The targeting of plant cellular systems by injected type III effector proteins. Semin. Cell Dev. Biol. 20:1055-1063.

Lewis, L. A., Polanski, K., de Torres-Zabala, M., Jayaraman, S., Bowden, L., Moore, J., Penfold, C. A., Jenkins, D. J., Hill, C., Baxter, L., Kulasekaran, S., Truman, W., Littlejohn, G., Prusinska, J., Mead, A., Steinbrenner, J., Hickman, R., Rand, D., Wild, D. L., Ott, S., BuchananWollaston, V., Smirnoff, N., Beynon, J., Denby, K., and Grant, M. 2015. Transcriptional dynamics driving MAMP-triggered immunity and pathogen effector-mediated immunosuppression in Arabidopsis leaves following infection with Pseudomonas syringae pv. tomato DC3000. Plant Cell 27:3038-3064

Li, J., Trivedi, P., and Wang, N. 2016. Field evaluation of plant defense inducers for the control of citrus Huanglongbing. Phytopathology 106 37-46.

Macho, A. P., and Zipfel, C. 2015. Targeting of plant pattern recognition receptor-triggered immunity by bacterial type-III secretion system effectors. Curr. Opin. Microbiol. 23:14-22.

Mafra, V., Martins, P. K., Francisco, C. S., Ribeiro-Alves, M., FreitasAstúa, J., and Machado, M. A. 2013. Candidatus Liberibacter americanus induces significant reprogramming of the transcriptome of the susceptible citrus genotype. BMC Genomics 14:247.

Makarova, K. S., and Koonin, E. V. 2003. Comparative genomics of Archaea: How much have we learned in six years, and what's next? Genome Biol. 4:115.

Manjunath, K. L., Halbert, S. E., Ramadugu, C., Webb, S., and Lee, R. F. 2008. Detection of 'Candidatus Liberibacter asiaticus' in Diaphorina citri and its importance in the management of citrus huanglongbing in Florida. Phytopathology 98:387-396.

McCann, H. C., Nahal, H., Thakur, S., and Guttman, D. S. 2012. Identification of innate immunity elicitors using molecular signatures of natural selection. Proc. Natl. Acad. Sci. U.S.A. 109:4215-4220.

McCollum, G., Hilf, M., Irey, M., Luo, W., and Gottwald, T. 2016. Susceptibility of sixteen citrus genotypes to 'Candidatus Liberibacter asiaticus'. Plant Dis. 100:1080-1086.

Mignolet-Spruyt, L., Xu, E., Idänheimo, N., Hoeberichts, F. A., Mühlenbock, P., Brosché, M., Van Breusegem, F., and Kangasjärvi, J. 2016. Spreading the news: Subcellular and organellar reactive oxygen species production and signalling. J. Exp. Bot. 67: 3831-3844

Minibayeva, F., Kolesnikov, O., Chasov, A., Beckett, R. P., Lüthje, S., Vylegzhanina, N., Buck, F., and Böttger, M. 2009. Wound-induced apoplastic peroxidase activities: Their roles in the production and detoxification of reactive oxygen species. Plant Cell Environ. 32: 497-508.

Mott, G. A., Desveaux, D., and Guttman, D. S. 2018. A high-sensitivity, microtiter-based plate assay for plant pattern-triggered immunity. Mol. Plant-Microbe Interact. 31:499-504.

Mott, G. A., Thakur, S., Smakowska, E., Wang, P. W., Belkhadir, Y., Desveaux, D., and Guttman, D. S. 2016. Genomic screens identify a new phytobacterial microbe-associated molecular pattern and the cognate Arabidopsis receptor-like kinase that mediates its immune elicitation. Genome Biol. 17:98.

Nandeeshkumar, P., Sudisha, J., Ramachandra, K. K., Prakash, H. S., Niranjana, S. R., and Shekar, S. H. 2008. Chitosan induced resistance to downy mildew in sunflower caused by Plasmopara halstedii. Physiol. Mol. Plant Pathol. 72:188-194.
Naranjo, E., Merfa, M. V., Ferreira, V., Jain, M., Davis, M. J., Bahar, O. Gabriel, D. W., and De La Fuente, L. 2019. Liberibacter crescens biofilm formation in vitro: Establishment of a model system for pathogenic 'Candidatus Liberibacter spp.'. Sci. Rep. 9:5150.

Nehela, Y., Hijaz, F., Elzaawely, A. A., El-Zahaby, H. M., and Killiny, N. 2016. Phytohormone profiling of the sweet orange (Citrus sinensis (L.) Osbeck) leaves and roots using GC-MS-based method. J. Plant Physiol. 199:12-17.

O’Brien, H. E., Thakur, S., Gong, Y., Fung, P., Zhang, J., Yuan, L., Wang, P. W., Yong, C., Scortichini, M., and Guttman, D. S. 2012. Extensive remodeling of the Pseudomonas syringae pv. avellanae type III secretome associated with two independent host shifts onto hazelnut BMC Microbiol. 12:141.

Page, A. J., Cummins, C. A., Hunt, M., Wong, V. K., Reuter, S., Holden, M. T., Fookes, M., Falush, D., Keane, J. A., and Parkhill, J. 2015. Roary: Rapid large-scale prokaryote pan genome analysis. Bioinformatics 31: 3691-3693.

Palazzotto, E., and Weber, T. 2018. Omics and multi-omics approaches to study the biosynthesis of secondary metabolites in microorganisms. Curr. Opin. Microbiol. 45:109-116.

Pelz-Stelinski, K. S., Brlansky, R. H., Ebert, T. A., and Rogers, M. E. 2010. Transmission parameters for Candidatus Liberibacter asiaticus by Asian citrus psyllid (Hemiptera: Psyllidae). J. Econ. Entomol. 103: 1531-1541.

Piel, J., Hui, D., Wen, G., Butzke, D., Platzer, M., Fusetani, N., and Matsunaga, S. 2004. Antitumor polyketide biosynthesis by an uncultivated bacterial symbiont of the marine sponge Theonella swinhoei. Proc. Natl. Acad. Sci. U.S.A. 101:16222-16227

Pitino, M., Armstrong, C. M., and Duan, Y. 2015. Rapid screening for citrus canker resistance employing pathogen-associated molecular patterntriggered immunity responses. Hortic. Res. 2:15042.

Quintana-Rodriguez, E., Duran-Flores, D., Heil, M., and CamachoCoronel, X. 2018. Damage-associated molecular patterns DAMPs as future plant vaccines that protect crops from pests. Sci. Hortic. 237: 207-220.

Ramadugu, C., Keremane, M. L., Halbert, S. E., Duan, Y. P., Roose, M. L., Stover, E., and Lee, R. F. 2016. Long-term field evaluation reveals Huanglongbing resistance in Citrus relatives. Plant Dis. 100: 1858-1869.

Schreiber, K. J., Baudin, M., Hassan, J. A., and Lewis, J. D. 2016. Die another day: Molecular mechanisms of effector-triggered immunity elicited by type III secreted effector proteins. Semin. Cell Dev. Biol. 56: 124-133.

Seemann, T. 2014. Prokka: Rapid prokaryotic genome annotation. Bioinformatics 30:2068-2069.

Segonzac, C., Feike, D., Gimenez-Ibanez, S., Hann, D. R., Zipfel, C., and Rathjen, J. P. 2011. Hierarchy and roles of pathogen-associated molecular pattern-induced responses in Nicotiana benthamiana. Plant Physiol. 156:687-699.

Segonzac, C., and Zipfel, C. 2011. Activation of plant pattern-recognition receptors by bacteria. Curr. Opin. Microbiol. 14:54-61.

Selvaraj, V., Maheshwari, Y., Hajeri, S., Chen, J., McCollum, T. G., and Yokomi, R. 2018. Development of a duplex droplet digital PCR assay for absolute quantitative detection of "Candidatus Liberibacter asiaticus". PLoS One 13:e0197184.

Shang-Guan, K., Wang, M., Htwe, N. M. P. S., Li, P., Li, Y., Qi, F., Zhang, D., Cao, M., Kim, C., Weng, H., Cen, H., Black, I. M., Azadi, P., Carlson, R. W., Stacey, G., and Liang, Y. 2018. Lipopolysaccharides trigger two successive bursts of reactive oxygen species at distinct cellular locations. Plant Physiol. 176:2543-2556.

Shi, Q., Febres, V. J., Jones, J. B., and Moore, G. A. 2015. Responsiveness of different citrus genotypes to the Xanthomonas citri ssp. citri-derived pathogen-associated molecular pattern (PAMP) flg22 correlates with resistance to citrus canker. Mol. Plant Pathol. 16:507-520.

Shi, Q., Febres, V. J., Jones, J. B., and Moore, G. A. 2016. A survey of FLS2 genes from multiple citrus species identifies candidates for enhancing disease resistance to Xanthomonas citri ssp. citri. Hortic. Res. 3:16022.

Shi, Q., Febres, V. J., Zhang, S., Yu, F., McCollum, G., Hall, D. G., Moore, G. A., and Stover, E. 2018. Identification of gene candidates associated with huanglongbing tolerance, using 'Candidatus Liberibacter asiaticus' flagellin 22 as a proxy to challenge citrus. Mol. Plant-Microbe Interact. 31:200-211.

Sinha, P. K., Castro-Guerrero, N., Patki, G., Sato, M., Torres-Bacete, J., Sinha, S., Miyoshi, H., Matsuno-Yagi, A., and Yagi, T. 2015. Conserved amino acid residues of the NuoD segment important for structure and function of Escherichia coli NDH-1 (complex I). Biochemistry 54: 753-764. 
Spero, M. A., Aylward, F. O., Currie, C. R., and Donohue, T. J. 2015. Phylogenomic analysis and predicted physiological role of the protontranslocating NADH:quinone oxidoreductase (complex I) across bacteria. MBio 6:e00389-15.

Tao, Y., Xie, Z., Chen, W., Glazebrook, J., Chang, H.-S., Han, B., Zhu, T., Zou, G., and Katagiri, F. 2003. Quantitative nature of Arabidopsis responses during compatible and incompatible interactions with the bacterial pathogen Pseudomonas syringae. Plant Cell 15:317-330.

Toruño, T. Y., Stergiopoulos, I., and Coaker, G. 2016. Plant-pathogen effectors: Cellular probes interfering with plant defenses in spatial and temporal manners. Annu. Rev. Phytopathol. 54:419-441.

Tsuda, K., and Katagiri, F. 2010. Comparing signaling mechanisms engaged in pattern-triggered and effector-triggered immunity. Curr. Opin. Plant Biol. 13:459-465.

Wang, N., Pierson, E. A., Setubal, J. C., Xu, J., Levy, J. G., Zhang, Y., Li, J., Rangel, L. T., and Martins, J., Jr. 2017. The Candidatus Liberibacter-host interface: Insights into pathogenesis mechanisms and disease control. Annu. Rev. Phytopathol. 55:451-482.

Wang, N., and Trivedi, P. 2013. Citrus huanglongbing: A newly relevant disease presents unprecedented challenges. Phytopathology 103: 652-665.

Wang, Y., Zhou, L., Yu, X., Stover, E., Luo, F., and Duan, Y. 2016. Transcriptome profiling of Huanglongbing (HLB) tolerant and susceptible citrus plants reveals the role of basal resistance in HLB tolerance. Front. Plant Sci. 7:933.

Wohlgemuth, H., Mittelstrass, K., Kschieschan, S., Bender, J., Weigel, H. J., Overmyer, K., Kangasjärvi, J., Sandermann, H., and Langebartels, C. 2002. Activation of an oxidative burst is a general feature of sensitive plants exposed to the air pollutant ozone. Plant Cell Environ. 25: 717-726.

Wright, C. A., and Beattie, G. A. 2004. Pseudomonas syringae pv. tomato cells encounter inhibitory levels of water stress during the hypersensitive response of Arabidopsis thaliana. Proc. Natl. Acad. Sci. U.S.A. 101: 3269-3274.

Xin, X. F., Kvitko, B., and He, S. Y. 2018. Pseudomonas syringae: What it takes to be a pathogen. Nat. Rev. Microbiol. 16:316-328.

Yang, Z. 2007. PAML 4: Phylogenetic analysis by maximum likelihood. Mol. Biol. Evol. 24:1586-1591.

Yang, Z., Nielsen, R., Goldman, N., and Pedersen, A.-M. K. 2000. Codonsubstitution models for heterogeneous selection pressure at amino acid sites. Genetics 155:431-449.

Yang, Z., Wong, W. S. W., and Nielsen, R. 2005. Bayes empirical Bayes inference of amino acid sites under positive selection. Mol. Biol. Evol. 22:1107-1118.

Yu, Q., Chen, C., Du, D., Huang, M., Yao, J., Yu, F., Brlansky, R. H., and Gmitter, F. G., Jr. 2017. Reprogramming of a defense signaling pathway in rough lemon and sweet orange is a critical element of the early response to 'Candidatus Liberibacter asiaticus'. Hortic. Res. 4: 17063.

Zeng, W., Brutus, A., Kremer, J. M., Withers, J. C., Gao, X., Jones, A. D., and He, S. Y. 2011. A genetic screen reveals Arabidopsis stomatal and/or apoplastic defenses against Pseudomonas syringae pv. tomato DC3000. PLoS Pathog. 7:e1002291.

Zhang, M., Powell, C. A., Zhou, L., He, Z., Stover, E., and Duan, Y. 2011 Chemical compounds effective against the citrus Huanglongbing bacterium 'Candidatus Liberibacter asiaticus' in planta. Phytopathology 101:1097-1103.

Zipfel, C., Robatzek, S., Navarro, L., Oakeley, E. J., Jones, J. D. G., Felix, G., and Boller, T. 2004. Bacterial disease resistance in Arabidopsis through flagellin perception. Nature 428:764-767.

Zou, H., Gowda, S., Zhou, L., Hajeri, S., Chen, G., and Duan, Y. 2012. The destructive citrus pathogen, 'Candidatus Liberibacter asiaticus' encodes a functional flagellin characteristic of a pathogen-associated molecular pattern. PLoS One 7:e46447. 